\title{
High-resolution inventory of technologies, activities, and emissions of coal-fired power plants in China from 1990 to 2010
}

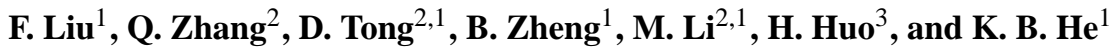 \\ ${ }^{1}$ State Key Joint Laboratory of Environment Simulation and Pollution Control, School of Environment, \\ Tsinghua University, Beijing, China \\ ${ }^{2}$ Ministry of Education Key Laboratory for Earth System Modeling, Center for Earth System Science, \\ Tsinghua University, Beijing, China \\ ${ }^{3}$ Institute of Energy, Environment and Economy, Tsinghua University, Beijing, China \\ Correspondence to: Q. Zhang (qiangzhang @ tsinghua.edu.cn)
}

Received: 2 May 2015 - Published in Atmos. Chem. Phys. Discuss.: 9 July 2015

Revised: 11 November 2015 - Accepted: 12 November 2015 - Published: 1 December 2015

\begin{abstract}
This paper, which focuses on emissions from China's coal-fired power plants during 1990-2010, is the second in a series of papers that aims to develop a highresolution emission inventory for China. This is the first time that emissions from China's coal-fired power plants were estimated at unit level for a 20 -year period. This inventory is constructed from a unit-based database compiled in this study, named the China coal-fired Power plant Emissions Database (CPED), which includes detailed information on the technologies, activity data, operation situation, emission factors, and locations of individual units and supplements with aggregated data where unit-based information is not available. Between 1990 and 2010, compared to a $479 \%$ growth in coal consumption, emissions from China's coal-fired power plants increased by 56,335 , and $442 \%$ for $\mathrm{SO}_{2}, \mathrm{NO}_{x}$, and $\mathrm{CO}_{2}$, respectively, and decreased by 23 and $27 \%$ for $\mathrm{PM}_{2.5}$ and $\mathrm{PM}_{10}$ respectively. Driven by the accelerated economic growth, large power plants were constructed throughout the country after 2000, resulting in a dramatic growth in emissions. The growth trend of emissions has been effectively curbed since 2005 due to strengthened emission control measures including the installation of flue gas desulfurization (FGD) systems and the optimization of the generation fleet mix by promoting large units and decommissioning small ones. Compared to previous emission inventories, CPED significantly improved the spatial resolution and temporal profile of the power plant emission inventory in China by extensive use of underlying data at unit level. The new inventory developed in this study will enable a close exami-
\end{abstract}

nation of temporal and spatial variations of power plant emissions in China and will help to improve the performances of chemical transport models by providing more accurate emission data.

\section{Introduction}

Bottom-up emission inventories, which are compiled from activity rates and emission factors, provide crucial information for understanding the variability of atmospheric compositions and for regulating climate and air quality policies. However, the current understanding of anthropogenic emissions in China is insufficient because of a lack of underlying data such as detailed activity rates and local measured emission factors (Zhao et al., 2011). This paper is the second in a series that aims to reduce these uncertainties and to improve the spatial and temporal resolution of bottom-up emission inventories in China. The first paper developed a high-resolution emission map for on-road vehicles (Zheng et al., 2014), and this paper focuses on coal-fired power plants.

Power plants have consumed approximately half of the total coal production in China over the past decade (China Energy Statistical Yearbook, National Bureau of Statistics (NBS), 1992-2011) and contributed significantly to the total national emissions of greenhouse gases and air pollutants (32\% of $\mathrm{CO}_{2}, 33 \%$ of $\mathrm{SO}_{2}, 33 \%$ of $\mathrm{NO}_{x}$, and $6 \%$ of $\mathrm{PM}_{2.5}$ in 2010, Y. Zhao et al., 2013). Therefore, developing a coalfired power plant emission inventory with high spatial and 
temporal resolution can significantly improve the accuracy of the anthropogenic emission inventory in China. In the meanwhile, because the power plant sector plays a key role in energy and environmental policies, a well-developed power plant database with accurate energy consumption and emission data could help to guide future policies and evaluate the dynamic changes in emissions induced by those policies.

As one of the major anthropogenic emitting sources, coalfired power plant emissions in China have been estimated in many national, regional, and global inventories. Early studies (Kato and Akimoto, 1992; Klimont et al., 2001; Hao et al., 2002; Ohara et al., 2007) used yearly activity data with fixed emission factors to estimate emissions, which ignored the fact that the net emission rates were changing rapidly with the emergence of new technologies into the market. In recent studies, technology-based methodologies and locally measured emission factors have been used to represent the dynamic changes in emissions, which has improved the accuracy of the magnitudes of and trends in power plant emissions throughout China (e.g., Zhang et al., 2007, 2009a; Klimont et al., 2009, 2013; Lei et al., 2011; Tian et al., 2013; Y. Zhao et al., 2013).

In addition to the accuracy of the magnitudes, accurate information for each generation unit (i.e., location, emissions) is also critical for a power plant inventory because power plant emissions are typically large, and improper treatment may lead to significant bias in the spatial distribution of emissions. Owing to the difficulties in acquiring information for all of the power plants in China, many bottom-up inventories only identified emissions from large power plants and allocated them according to their latitude and longitude coordinates, whereas emissions from other small units were distributed as area sources (e.g., Streets et al., 2003; Ohara et al., 2007; Zhang et al., 2009a; Lu et al., 2011). For the first time, Zhao et al. (2008) used unit-level coal consumption to calculate emissions of individual electric generation units for the years of 2000 and 2005 and assigned them to each location. Subsequent studies developed unit-based power plant emission inventories for $\mathrm{NO}_{x}$ for the period of 2005-2007 (Wang et al., 2012) and for $\mathrm{SO}_{2}, \mathrm{NO}_{x}$, particulate matter and $\mathrm{PM}_{2.5}$ for 2011 (Chen et al., 2014). The Carbon Monitoring for Action (CARMA) database (Wheeler and Ummel, 2008), a global power plant database at the factory level, has been widely used in bottom-up emission inventories to allocate power plant emissions (EC-JRC/PBL, 2011; Oda and Maksyutov, 2011; Kurokawa et al., 2013; Wang et al., 2013). However, the accuracy of the emission strengths and locations in the CARMA database is questionable given that it is not a scientific-level data set that has undergone critical evaluation (Oda and Maksyutov, 2011; Gurney, 2012).

There are two major deficiencies in the current power plant inventories throughout China for revealing emissions at the unit level. First, owing to the lack of detailed information at the unit level, emissions from each plant are generally divided by the provincial totals according to capacity (e.g.,
Zhang et al., 2009a; Lu et al., 2011), which ignores the differences in the emission rates among units introduced by different technologies. Second, in a rapidly developing country such as China, emission factors for a given power plant may change over time as new combustion or emission control technologies are applied following the implementation of new emission standards. Therefore, these time-dependent parameters should be included dynamically when constructing an accurate emission trend for the power plants in China.

The purpose of this study was to develop a high-resolution inventory of the technologies, activity rates, and emissions of coal-fired power plants in China for the period of 1990-2010 using extensive underlying data at the unit level, supplemented with aggregated data where unit-based information is not available. This is the first time that coal-fired power plant emissions in China were estimated for each unit from the bottom-up for a 2-decade period. We construct a unit-based database, called the China coal-fired Power plant Emissions Database (CPED), by collecting information regarding the technologies, activity data, emission factors, and locations of individual electricity generating units. To improve the accuracy of the emission estimates at the unit level, the database developed in this study includes not only the type and removal efficiency of emission control equipment for each unit but also the operating conditions of the equipment (i.e., when the equipment was commissioned).

Based on the unit-specific parameters from the CPED (e.g., unit capacity, boiler type, operation and phasing-out procedures, the sulfur content and ash content of coal, the type of emission control equipment and the time at which the equipment was commissioned, along with its removal efficiency), the $\mathrm{SO}_{2}, \mathrm{NO}_{x}$, fine particulate matter $\left(\mathrm{PM}_{2.5}\right)$, $\mathrm{PM}_{10}$, and $\mathrm{CO}_{2}$ emissions were estimated on a monthly basis for each coal-fired power generation unit over the period of 1990-2010. CO, Volatile Organic Compound (VOC), Black Carbon (BC) and Organic Carbon (OC) emissions were not estimated in this work because coal-fired power plants contributed very small fractions to national total emissions of these species (e.g., less than $1 \%$ of total $\mathrm{CO}$ emissions in 2010 estimated by Y. Zhao et al., 2013).

\section{Unit-based methodology and data}

The CPED database developed in this study consists of 7657 coal-fired electric-generating units in mainland China, including $\sim 5700$ units in use in 2010 and $\sim 1900$ units that have retired since 2005. The $\mathrm{SO}_{2}, \mathrm{NO}_{x}, \mathrm{PM}_{2.5}, \mathrm{PM}_{10}$ and $\mathrm{CO}_{2}$ emissions from a specific unit in a given month from 1990 to 2010 were estimated using the following equation: 


$$
\begin{aligned}
& \text { Emis }_{s, y, m}=U \times P \times\left(H_{0} / H_{y}\right) \times T_{y} \times f_{m, y} \times \mathrm{EF}_{s, k, y} \\
& \times \prod_{n}\left(1-\eta_{n, s} \times \tau_{n, m, y}\right),
\end{aligned}
$$

where $s$ represents the emission species, $k$ represents the boiler type, $n$ represents the emission abatement technology type, $y$ represents the year, and $m$ represents the month. $U$ is the unit capacity, in MW, $P$ is the coal consumption rate presented in grams coal equivalent per $\mathrm{kWh}$ supplied $\left(\right.$ gce $\left.\mathrm{kWh}^{-1}\right), H$ is the heating value of coal used for each unit in $\mathrm{kJ} \mathrm{g}^{-1}, H_{0}$ is the heating value of standard coal, which is $29.27 \mathrm{~kJ} \mathrm{gce}^{-1}$, and the ratio of $H_{0}$ to $H$ converts the coal equivalent (gce) to the physical quantity of coal (gram). $T$ is the annual operation in hours, the product of $U$ and $T$ is the annual electricity generation, $f$ is the monthly fraction of annual electricity generation, and EF is the unabated emission factor, in $\mathrm{g} \mathrm{kg}^{-1}$ of coal. The parameter $\eta$ is the removal efficiency of the abatement equipment, and $\tau$ is the state factor for the abatement equipment; $\tau=1$ when the equipment is present and running, otherwise $\tau=0$.

\subsection{Activity rates}

Detailed activity data are available for each generation unit for the period of 2005-2010 from China's Ministry of Environmental Protection (MEP; unpublished data, referred to hereafter as the MEP database). We used the MEP database as the basis of deriving the activity rates for each unit for the period of 1990-2010 from a combination of different data sets. The capacity $(U)$ and operational status (when the unit was commissioned/decommissioned) for each unit were collected from the MEP database and the National Development and Reform Commission (NDRC, 2013). The annual coal use and power generation of each unit from 2005 to 2010 were also obtained from the MEP database and were used to calculate the coal consumption rate $(P)$ for each unit. The details about the generation unit fleet mix according to capacity size and efficiency are presented in Sect. 3.1.

The heating value of the coal $(H)$ used for each unit in 2010 was obtained from the MEP database. In other years for which the unit-level data are not available, the average heating values of the coal used in power plants were derived by year and by province from the energy statistics (NBS, 19922011) and were then adapted to scale the 2010 value of each unit to the corresponding years. The heating values of coal have decreased remarkably since 2007 (from $20.0 \mathrm{~kJ} \mathrm{~g}^{-1}$ coal in 2007 to $18.8 \mathrm{~kJ} \mathrm{~g}^{-1}$ coal in 2010 as the national average), indicating the downgraded coal quality in the power sector due to a shortage of coal induced by a surge of electricity demand in recent years (Liu, 2007; Shen and Song, 2010). Table S3 in the Supplement summarizes the provincial average of coal consumption rate and heating value for the year 2010 .
The annual operating hours ( $T$ ) for each unit from 2005 to 2010 were obtained from the MEP database. In other years for which the unit-based data are not available, operating hours were scaled from the 2005 data according to the ratio of the provincial average operating hours in 2005 and the corresponding year. The provincial average operating hours before 2005 were estimated from the provincial total coal consumption (NBS, 1992-2011) and the product of the corresponding unit capacity and the coal consumption rate obtained from our database. It should be noted that emissions estimates prior to 2005 are more uncertain because the extrapolated parameters were used.

The monthly fraction of annual electricity generation $(f)$ is quantified by province, due to the lack of data at unit level. For 2003-2010, $f$ was derived from the statistics (NBS, 2013) and was applied to the units with adjustments if the unit was commissioned or decommissioned within that year, following Eq. (2). For the years prior to 2003, a monthly climatological profile of the 2003-2007 average was used.

$f_{m}=\frac{\gamma_{m} F_{m}}{\sum_{m=1}^{12} \gamma_{m} F_{m}}$,

where $m$ represents the month. $f$ and $F$ is the monthly fraction of annual electricity generation at unit and province level respectively. $\gamma$ is the state factor for the unit; $\gamma=1$ when the unit has been commissioned and in operation, otherwise $\gamma=0$.

Coordinates of each unit (latitude and longitude) were obtained from the MEP database and then individually validated using Google Earth to ensure that the accurate locations are presented in the CPED.

\subsection{Emission factors}

\subsection{1 $\mathrm{SO}_{2}$}

The unabated $\mathrm{SO}_{2}$ emission factors for a specific unit were estimated via the sulfur mass balance approach using the following equation:

$\mathrm{EF}_{\mathrm{SO}_{2}, y}=2 \times \mathrm{SCC}_{y} \times(1-\mathrm{Sr})$,

where $y$ represents the year, $\mathrm{EF}_{\mathrm{SO}_{2}}$ is the unabated $\mathrm{SO}_{2}$ emission factor in $\mathrm{g} \mathrm{kg}^{-1}$, SCC is the sulfur content of coal, and $\mathrm{Sr}$ is the fraction of sulfur retention in ash.

The SCC for each unit from 2005 to 2010 was obtained from the MEP database. The SCC ranges widely, with a mean value of $0.95 \%$. The SCC in the northeast power plants is lowest, whereas the SCC in the central and south power plants is significantly higher than that of plants in other regions, reflecting the different sulfur content in coal production in the various regions (Tang et al., 2008). For the years before 2005, the SCC for each unit was scaled from 2005 data using the ratio of the provincial average SCC in 2005 
and the corresponding year. The provincial average SCC before 2005 was calculated from the sulfur contents of coal production in each province using the coal transportation matrix approach (Zhang et al., 2012). The sulfur retention ratio was assumed to be $15 \%$ for all of the units (Zhang et al., 2009a; Lu et al., 2010) because of the lack of unit-specific data.

Flue gas desulfurization (FGD) systems have been widely installed in coal-fired power plants in China since 2005. This has been the most important step for the emission reduction plan to reduce national $\mathrm{SO}_{2}$ emissions by $10 \%$ during the 11th Five-Year Plan (2005-2010). In this study, the operating conditions of FGD for each unit were obtained from the MEP database. The actual $\mathrm{SO}_{2}$ removal efficiencies for each unit in 2010 were also obtained from the MEP database and were applied to every year because no data are available for the other years. The coal-consumption weighted mean $\mathrm{SO}_{2}$ removal efficiency of all FGD facilities in 2010 is $78 \%$. Surveys and satellite observations confirmed that some of the early installed FGD facilities were not actually in operation prior to 2008 as the factories reported (Xu et al., 2009; Li et al., 2010; Xu, 2011), implying that our assumption may underestimate the $\mathrm{SO}_{2}$ emissions from 2005 to 2007 for some units. $\mathrm{SO}_{2}$ emissions can also be removed from wet scrubbers as a co-benefit of particulate matter removal. In this study, we assumed that the removal efficiency of wet scrubbers for $\mathrm{SO}_{2}$ is $20 \%$ (Yao, 1989; Xie, 1995).

\subsubsection{NO $\mathrm{N}_{x}$}

$\mathrm{NO}_{x}$ emission rates from coal-fired power plants vary significantly by boiler size, combustion technology, and coal type. In this study, we classified the units into three categories by size: large units $(\geq 300 \mathrm{MW})$, medium units $(\geq 100$ and $<300 \mathrm{MW})$, and small units $(<100 \mathrm{MW})$. We also classified the units into three categories by combustion technology (traditional low- $\mathrm{NO}_{x}$ burner technology (traditional LNB), advanced LNB, and without LNB (non-LNB)) and into two categories by coal type (bituminous and anthracite). Table 1 summarizes the measured $\mathrm{NO}_{x}$ emission factors in China's coal-fired power plants from each category.

Selective catalytic reduction (SCR) and selective noncatalytic reduction (SNCR) are two major de- $\mathrm{NO}_{x}$ technologies used in coal-fired power plants. In 2010, 194 coal-fired electric generation units ( $13 \%$ of the national total capacity) with a total capacity of $84 \mathrm{GW}$ were equipped with SCR or SNCR. However, the actual operating conditions of the installed de$\mathrm{NO}_{x}$ devices are questionable due to the lack of inspections by local environmental protection bureaus before 2010. Our recent study also found that satellite-recorded tropospheric $\mathrm{NO}_{2}$ columns around the power plants with de- $\mathrm{NO}_{x}$ devices were stable before 2010, indicating the poor operating conditions of these devices (Wang et al., 2015). In this study, we assumed that the de- $\mathrm{NO}_{x}$ devices were not in operation until 2010 by setting the state factor in Eq. (1) to 0 .
Prior to 2010, LNB technology was the only widely used technology in China's power plants to reduce $\mathrm{NO}_{x}$ emissions. Beginning in 1997, the use of LNB technologies in China's power plants increased, following the strengthened emission standards for thermal power plants (State Environmental Protection Administration of China (SEPA), 1996, 2003) in China. Since approximately 2005, newly established large generation units have been widely equipped with advanced LNB technologies, i.e., the stereo-staged combustion technology (Zhang et al., 2009b) and the so-called "double-scale" combustion technology, which can significantly reduce the emission rates of $\mathrm{NO}_{x}$. Recent measurements of China's coal-fired power plants confirmed that $\mathrm{NO}_{x}$ emission rates from large units with advanced LNB technologies are remarkably lower than units with traditional LNB technologies (e.g., Zhu et al., 2009; Zhu, 2011; Cao and Liu, 2011; see Table 1).

Based on the discussion above, we assigned the appropriate LNB technology to each generation unit according to the following assumptions, given that the LNB information was absent from the MEP database. (1) All large units constructed before 2006 are equipped with traditional LNB, and units constructed after 2006 are equipped with advanced LNB; (2) medium units constructed after 1997 are equipped with traditional LNB to meet the emission standards (SEPA, 1996), whereas units constructed before 1997 are not equipped with LNB; and (3) no small units are equipped with LNB during the study period. We then used the emission factors presented in Table 1 to calculate the $\mathrm{NO}_{x}$ emissions for each unit.

\subsubsection{PM}

PM emissions were estimated for two size fractions: $\mathrm{PM}_{2.5}$ and $\mathrm{PM}_{2.5-10}$ (PM with diameter more than $2.5 \mu \mathrm{m}$ but less than $10 \mu \mathrm{m}$, coarse particles). The unabated emission factor of PM was calculated using the following equation:

$\mathrm{EF}_{k, d}=\mathrm{AC} \times\left(1-\mathrm{ar}_{k}\right) \times f_{k, d}$,

where $k$ represents the boiler type, $d$ represents the diameter range of $\mathrm{PM} ; \mathrm{EF}_{d}$ is the emission factor of $\mathrm{PM}$ in diameter $d$, AC is the ash content of coal, ar is the mass fraction of retention ash, and $f_{d}$ is the mass fraction of PM in diameter $d$ to the total particulate matter in fly ash.

When calculating PM emissions, coal-fired generation units are classified into three boiler types: pulverized coal boilers, circulating fluidized beds, and grate furnaces. The boiler-type information for each unit was obtained from the MEP database. For each boiler type, the fraction of retention ash was derived from the Greenhouse Gas and Air Pollution Interactions and Synergies (GAINS) database (Klimont et al., 2002; Amann et al., 2011), with values of 20, 44, and $85 \%$ for pulverized coal boilers, circulating fluidized beds, and grate furnaces, respectively. The mass fraction of PM in diameter $d$ to total particulate matter in fly ash was derived from the GAINS (Klimont, et al., 2002; Amann et al., 
Table 1. Summary of $\mathrm{NO}_{x}$ emission factors for different types of coal-fired power plants.

\begin{tabular}{|c|c|c|c|c|c|}
\hline Unit size & $\begin{array}{l}\text { Combustion } \\
\text { technology }\end{array}$ & Bituminous coal, $\mathrm{g} \mathrm{kg}^{-1^{\mathrm{a}}}$ & $\begin{array}{l}\text { Average emission } \\
\text { factor, } \mathrm{g} \mathrm{kg}^{-1^{\mathrm{a}}}\end{array}$ & Anthracite coal, $\mathrm{g} \mathrm{kg}^{-1^{\mathrm{a}}}$ & $\begin{array}{l}\text { Average emission } \\
\text { factor, } \mathrm{g} \mathrm{kg}^{-1^{\mathrm{a}}}\end{array}$ \\
\hline \multirow{2}{*}{ Large $(\geq 300 \mathrm{MW})$} & Advanced LNB ${ }^{b}$ & $2.88^{1}, 3.05^{2}, 3.28^{3}, 3.55^{4}, 4.13^{5}, 4.17^{6}, 4.64^{7}$ & 4.06 & $6.14^{7}, 6.58^{4}, 6.99^{8}$ & 6.50 \\
\hline & Traditional LNB & $4.40^{9}, 4.98^{10}, 5.23^{11}, 5.06^{12}, 5.65^{8}, 7.78^{4}$ & 5.08 & $4.61^{11}, 4.99^{12}, 7.77^{7}, 7.94^{8}, 8.05^{10}, 8.73^{9}$ & 8.04 \\
\hline Medium $(\geq 100 \mathrm{MW}$ & Traditional LNB & $4.34^{10}, 5.52^{11}, 6.97^{13}$ & 6.78 & $7.07^{11}, 7.56^{10}$ & 7.29 \\
\hline and $<300 \mathrm{MW})$ & Non-LNB & $5.46^{14}, 8.12^{11}$ & 7.63 & $8.25^{10}, 12.11^{11}$ & 10.46 \\
\hline Small $(<100 \mathrm{MW})$ & Non-LNB & $6.55^{15}, 6.88^{11}$ & 6.66 & $10.01^{15}, 11.50^{11}$ & 10.50 \\
\hline
\end{tabular}

Table 2. Summary of the mass fractions of particulate matter of different size fractions to the total particulate matter in fly ash for different types of boilers ${ }^{\mathrm{a}}$; values are given as percentages (\%).

\begin{tabular}{lrrr}
\hline Size & \multicolumn{3}{c}{ Boiler type } \\
\cline { 2 - 4 } fraction & $\begin{array}{r}\text { Pulverized } \\
\text { boilers }\end{array}$ & $\begin{array}{r}\text { Circulating } \\
\text { fluidized beds }\end{array}$ & $\begin{array}{r}\text { Grate } \\
\text { furnaces }\end{array}$ \\
\hline $\mathrm{PM}_{>10}$ & 77 & 71 & 63 \\
$\mathrm{PM}_{2.5-10}$ & 17 & 22 & 23 \\
$\mathrm{PM}_{2.5}$ & 6 & 7 & 14 \\
\hline
\end{tabular}

a Data sources: Klimont et al. (2002) and Zhao et al. (2010).

2011) and local databases (Zhao et al., 2010), as presented in Table 2. The ash content of coal for each unit in 2010 was obtained from the MEP database and was applied to every year. Table S3 presents the provincial average of coal sulfur content and ash content for the year 2010.

The four types of technologies used in power plants to remove particulate matter are cyclones, wet scrubbers, electrostatic precipitators, and bag filters. The technology type for each unit was obtained from the MEP database. The removal efficiencies of each technology were obtained from our previous study (Lei et al., 2011) and are shown in Table 3. Particulate matter can also be removed via wet FGD as a co-benefit of $\mathrm{SO}_{2}$ removal. In this study, we assume the same $\mathrm{PM}_{2.5}$ removal efficiency for wet FGD equipment as that for wet scrubbers (Zhao et al., 2010). The uncertainty of the effect of the assumption on PM emissions was discussed in Sect. 4.1.

\subsection{4 $\mathrm{CO}_{2}$}

The emission factor for $\mathrm{CO}_{2}$ was calculated using guidelines from the Intergovernmental Panel on Climate Change (IPCC, 2006), as follows:

$\mathrm{EF}_{\mathrm{CO}_{2}, y}=A \times O \times 44 / 12 \times H_{y}$,

where $y$ is the year, $\mathrm{EF}_{\mathrm{CO}_{2}}$ is the $\mathrm{CO}_{2}$ emission factor in $\mathrm{g} \mathrm{kg}^{-1}, A$ is the carbon content in $\mathrm{kg} \mathrm{CGJ}^{-1}, O$ is the oxidization rate, and $H$ is the heating value in $\mathrm{kJ} \mathrm{g}^{-1}$ of coal. In this study, we used 25.8 and $26.7 \mathrm{~kg} \mathrm{C} \mathrm{GJ}^{-1}$ for the carbon contents of bituminous and anthracite coal, respectively, and $100 \%$ for the oxidization rate; these values were obtained
Table 3. Removal efficiencies of different control technologies for $\mathrm{SO}_{2}$ and particulate matter; values are given as percentages (\%).

\begin{tabular}{|c|c|c|c|c|}
\hline Technology & $\mathrm{SO}_{2}$ & $\mathrm{PM}_{2.5}$ & $\mathrm{PM}_{2.5-10}$ & $\mathrm{PM}_{>10}$ \\
\hline Cyclones & & 10 & 70 & 90 \\
\hline Wet scrubbers & 20 & 50 & 90 & 99 \\
\hline Electrostatic precipitators & & 93 & 98 & 99.5 \\
\hline $\mathrm{FGD}^{\mathrm{a}}$ & $78^{\mathrm{b}}$ & 50 & 90 & 99 \\
\hline Bag filters & & 99 & 99.5 & 99.9 \\
\hline
\end{tabular}

from the IPCC guidelines (IPCC, 2006). The data source of the coal heating value is presented in Sect. 2.1.

\subsection{Uncertainty analysis}

An uncertainty analysis was performed for our estimates using a Monte Carlo approach. The term "uncertainty" in this study refers to the lower and upper bounds of a $95 \%$ confidence interval (CI) around a central estimate. The Monte Carlo simulation uses specified probability distributions for each input parameter (e.g., activity data, emission factors) to generate random variables. The probability distribution of emissions is estimated according to a set of runs (10000 runs in this study) in a Monte Carlo framework with probability distributions of the input parameters (Lu et al., 2011; Zhao et al., 2011). Table S1 summarizes the probability distributions of all of the input parameters used to estimate the uncertainties of the national total emission estimates. For parameters with adequately measured data (e.g., $\mathrm{NO}_{x}$ emission factors), distribution functions were fitted from the distributions of those data. Probability distributions of other parameters were obtained from previous studies (Zhao et al., 2010, 2011; Lu et al., 2011) or were based on our own discretion.

Uncertainties associated with emission estimates could vary with time. The uncertainties for a unit in 1990 can be considered larger than the uncertainties in 2010, for which all of the specific information is available in the CPED. In this study, we also calculated the emission uncertainties of one selected generation unit for 2000 and 2010 to demonstrate the uncertainties at the unit level. The probability distributions of the unit-level parameters are presented in Table S2. In contrast to uncertainty analyses for national 


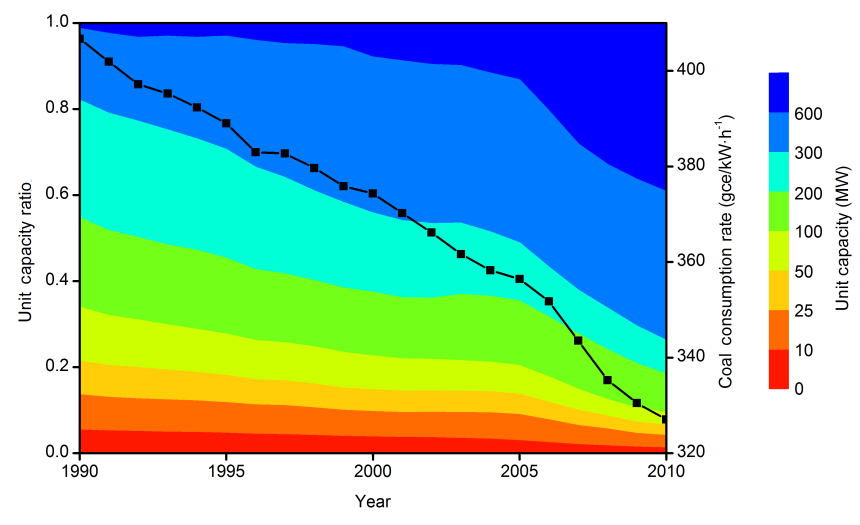

Figure 1. Trends in generation mix by capacity and the average coal consumption rates (black line) during 1990-2010.

total emissions, we used discrete distributions (i.e., "yes/no" distributions) to represent the probability distributions of the technologies which represent situations in which our assumptions about the technology for a specific unit are correct/incorrect.

\section{Results}

\subsection{Evolution of technologies in coal-fired power plants}

The energy efficiency of power plants in China has improved significantly over the past 2 decades. As shown in Fig. 1, the average coal consumption per unit electricity supplied decreased from $407 \mathrm{gce} \mathrm{kWh}^{-1}$ in 1990 to $327 \mathrm{gce} \mathrm{kWh}^{-1}$ in 2010, representing an improvement of $20 \%$ in energy efficiency over 20 years. This significant change could be attributed to the measures imposed by the Chinese government to encourage large-scale power units and to decommission small units. Figure 1 also presents the variation trend in the share of units of different sizes from 1990 to 2010. The share of the unit capacity of large units $(\geq 300 \mathrm{MW})$ increased sharply from $18 \%$ in 1990 to $74 \%$ in 2010 , whereas the share for small units ( $<100 \mathrm{MW})$ dropped to $9 \%$. In particular, the construction rate of large units equal to or larger than $600 \mathrm{MW}$ began to accelerate after 2005 . The capacity of units equal to or larger than $600 \mathrm{MW}$ was only $46 \mathrm{GW}$ in 2005 but increased to $262 \mathrm{GW}$ by 2010 , accounting for $39 \%$ of the national total capacity.

Figure 2 further examines the measures taken to drive the rapid change from 2005 to 2010. To fulfill the increasing demand for electricity, China constructed $417 \mathrm{GW}$ capacities from 2005 to 2010, of which $83 \%$ were large units. Figure $2 \mathrm{a}$ shows the growth of new power units since 2005. During this time, large units began to account for a greater share of new units. For all of the newly constructed units, the percentage of large units increased significantly from 29 to $49 \%$ from 2006 to 2010, whereas the percent of small units decreased from 57 to $41 \%$. In addition, the construction of new power generation capacity decreased from $86 \mathrm{GW}$ in 2006 to $66 \mathrm{GW}$ in 2010. In the meanwhile, China has taken measures to phase out low-efficient power plants. Figure $2 b$ illustrates that small units, especially those smaller than $25 \mathrm{MW}$, constitute the largest component of retired units, accounting for $89 \%$ of the number of retired units in 2006 . However, this ratio dropped to $62 \%$ in 2010 because the phase-out strategy gradually pursued larger units once the majority of units smaller than $25 \mathrm{MW}$ had been phased out. The average capacity of the units retired in 2010 was $40 \mathrm{MW}, 3$ times the value in 2006 (13 MW).

The great effort from 2005 to 2010 to construct large units and phase out small units significantly improved China's power plant energy efficiency, which is indicated by the shift of the coal consumption rate shown in Fig. 3. Figure 3 compares the number of plants by coal consumption rate (gce/kWh) in 2005 and 2010. In 2005, $62 \%$ of power plants in China had a coal consumption rate of 400-700 gce $\mathrm{kWh}^{-1}$, and $20 \%$ of power plants had a consumption rate greater than $700 \mathrm{gce} \mathrm{kWh}^{-1}$. In 2010, $57 \%$ of power plants in China

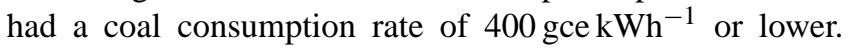
Generally, large units consume less coal than small units for the same amount of electricity generated because of the more advanced combustion technology used in larger units such as supercritical and ultra-supercritical technology. From 2005 to 2010, with the increase in the number of large units, the average coal consumption rate decreased from 356 to $327 \mathrm{gce} \mathrm{kWh}^{-1}$, representing an $8 \%$ total efficiency improvement from 2005 to 2010.

\subsection{Interannual emissions}

Figure 4 and Table 4 summarize the emissions of each species from China's coal-fired power plants during 19902010. The total coal consumption in China's coal-fired power plants increased significantly by $479 \%$ in China from 1990 to 2010, whereas $\mathrm{SO}_{2}$ emissions from the power plants increased by $56 \%, \mathrm{NO}_{x}$ emissions increased by $335 \%, \mathrm{CO}_{2}$ emissions increased by $442 \%, \mathrm{PM}_{2.5}$ emissions decreased by $23 \%$, and $\mathrm{PM}_{10}$ emissions decreased by $27 \%$ during the same period, indicating that significant technological changes occurred in the power sector. Table 4 also presents the variation in technology penetration rates and emission factors of coal-fired power plants from 1990 to 2010.

\subsection{1 $\mathrm{SO}_{2}$}

Figure 4 shows the $\mathrm{SO}_{2}$ emissions from power plants estimated in this study. From 1990 to 2005, $\mathrm{SO}_{2}$ emissions increased at an annual rate of $8 \%$, driven by the ever-increasing demand for electricity, at a growth rate of $10 \%$. The improved energy efficiency and co-benefit of wet scrubbers on $\mathrm{SO}_{2}$ removal slightly mitigated the emission growth trend. In 2005, to control emissions, China began to require the installation of FGD in power plants (Table 4). Therefore, 


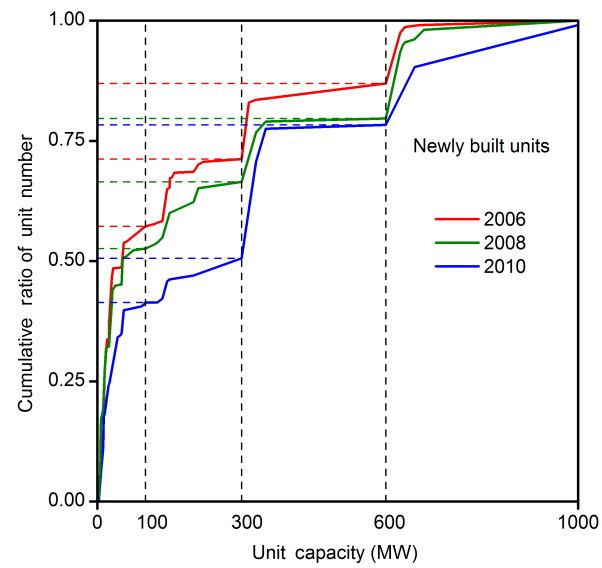

(a)

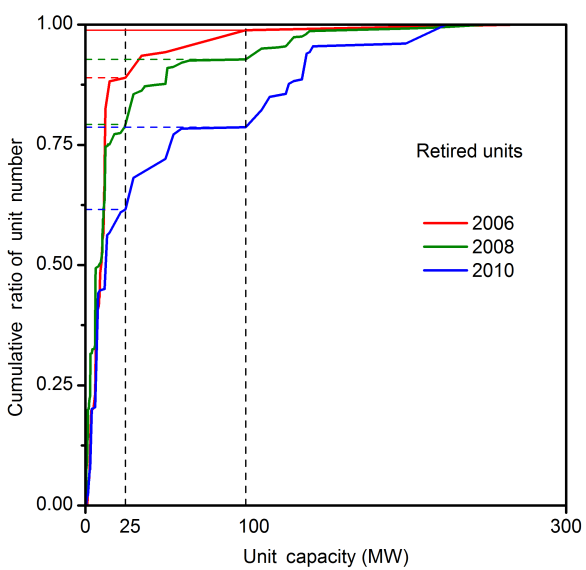

(b)

Figure 2. Cumulative ratio of unit number for (a) newly constructed and (b) retired electric-generating units for 2006, 2008, and 2010. The units are sorted according to ascending capacity along the $x$ axis.

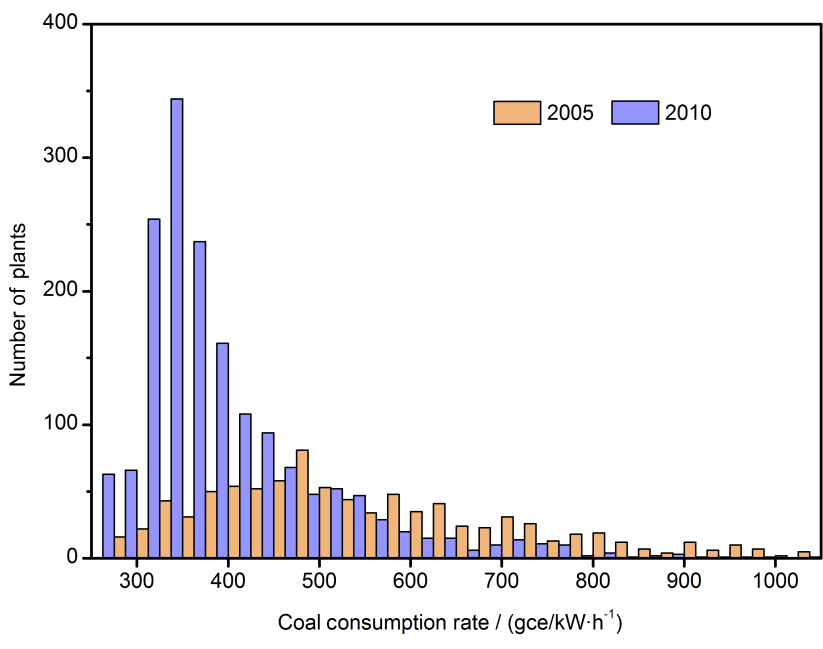

Figure 3. Distribution of coal consumption rates in coal-fired power plants in 2005 and 2010.

the $\mathrm{SO}_{2}$ emissions peaked at $16.7 \mathrm{Tg}$ in 2006 and began to decrease sharply. By $2010,84 \%$ of the total unit capacity in our database was equipped with FGD, which was estimated to reduce $\mathrm{SO}_{2}$ emissions to $7.7 \mathrm{Tg}, 54 \%$ lower than the 2006 emission level.

Figure 5 presents the FGD installation process. As shown in Fig. 5, in 2006, FGD was primarily installed for new units, and the share of unit capacity installed with FGD was $69 \%$ for new units, whereas it was only $15 \%$ for those over 10 years old. Influenced by the premium price for desulfurized electricity and the penalties incurred for non-desulfurized electricity since 2007 (Xu et al., 2009), the deployment of FGD sharply increased for new and aged units. As Fig. 5 shows, there was no difference in the FGD installation ratio between new and aged units younger than 20 years old in

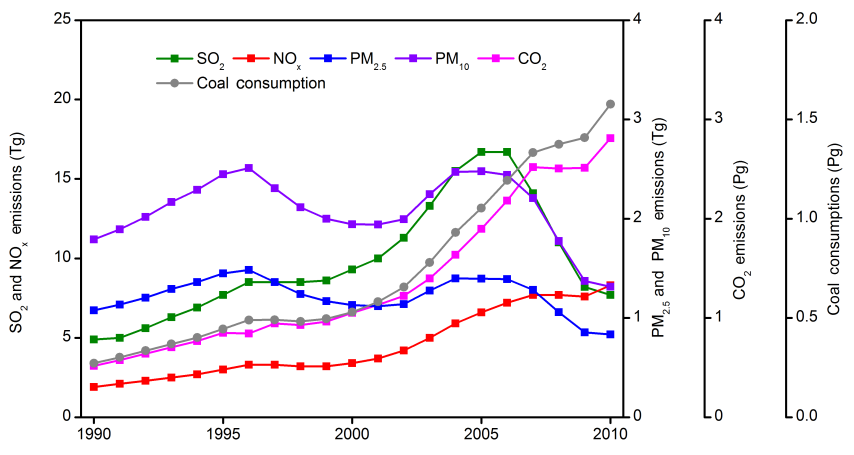

Figure 4. Coal consumption and emissions of $\mathrm{SO}_{2}, \mathrm{NO}_{x}, \mathrm{PM}_{2.5}$, $\mathrm{PM}_{10}$, and $\mathrm{CO}_{2}$ of coal-fired power plants in China from 1990 to 2010.

2010, and the share of the unit capacity with FGD reached $63 \%$ for units over 10 years old.

However, the $\mathrm{SO}_{2}$ removal efficiencies vary among the different units. As presented in Fig. 6, FGD equipped on larger units exhibited better $\mathrm{SO}_{2}$ removal efficiencies than that on small units. In 2010, the average $\mathrm{SO}_{2}$ removal efficiencies were approximately $80 \%$ for large units but only $60 \%$ for small units. Figure 7 presents the cumulative ratio of $\mathrm{SO}_{2}$ emissions by unit size for 2005 and 2010. The cumulative ratio of the unit capacity was comparable to that of the $\mathrm{SO}_{2}$ emissions in 2005 (Fig. 7a), but they differed significantly in 2010 (Fig. 7b). The capacity share of small units decreased from $20 \%$ in 2005 to $9 \%$ in 2010, but the contribution to the total $\mathrm{SO}_{2}$ emissions remained unchanged at $\sim 20 \%$. Before 2005, the emission contribution to $\mathrm{SO}_{2}$ of a power unit was largely dependent on its capacity because desulfurization devices were seldom employed at that time. Thus, the cumulative ratios of the unit capacity and $\mathrm{SO}_{2}$ emissions could be similar. However, in 2010, $92 \%$ of large units were equipped with FGD, which is considerably higher than the number of 
Table 4. Capacity sizes, technology penetrations, fuel qualities, emission factors, and emissions of coal-fired power plants in China from 1990 to 2010 .

\begin{tabular}{|c|c|c|c|c|c|c|c|c|c|c|}
\hline Category & Subcategory & 1990 & 1995 & 2000 & 2005 & 2006 & 2007 & 2008 & 2009 & 2010 \\
\hline \multirow{4}{*}{$\begin{array}{l}\text { Capacity } \\
\text { size }^{\mathrm{a}}\end{array}$} & $<100 \mathrm{MW}$ & $39.3 \%$ & $34.0 \%$ & $29.1 \%$ & $25.5 \%$ & $23.1 \%$ & $19.1 \%$ & $15.3 \%$ & $13.1 \%$ & $11.5 \%$ \\
\hline & $(100,300) \mathrm{MW}$ & $48.7 \%$ & $44.0 \%$ & $35.7 \%$ & $31.1 \%$ & $29.1 \%$ & $26.7 \%$ & $23.9 \%$ & $21.4 \%$ & $18.7 \%$ \\
\hline & $(300,600) \mathrm{MW}$ & $10.9 \%$ & $19.9 \%$ & $30.1 \%$ & $33.4 \%$ & $34.0 \%$ & $33.2 \%$ & $33.3 \%$ & $34.3 \%$ & $35.4 \%$ \\
\hline & $\geq 600 \mathrm{MW}$ & $1.2 \%$ & $2.2 \%$ & $5.0 \%$ & $9.9 \%$ & $13.8 \%$ & $21.0 \%$ & $27.5 \%$ & $31.2 \%$ & $34.4 \%$ \\
\hline \multirow{7}{*}{$\begin{array}{l}\text { Technology } \\
\text { penetration }^{\mathrm{a}}\end{array}$} & Traditional LNB & $12.0 \%$ & $22.1 \%$ & $38.7 \%$ & $53.7 \%$ & $51.8 \%$ & $46.6 \%$ & $44.2 \%$ & $42.1 \%$ & $39.4 \%$ \\
\hline & Advanced LNB & $0.0 \%$ & $0.0 \%$ & $0.0 \%$ & $0.0 \%$ & $7.4 \%$ & $19.8 \%$ & $29.2 \%$ & $35.9 \%$ & $42.0 \%$ \\
\hline & FGD & $0.1 \%$ & $1.0 \%$ & $2.1 \%$ & $12.2 \%$ & $29.5 \%$ & $49.9 \%$ & $70.2 \%$ & $81.9 \%$ & $85.6 \%$ \\
\hline & Cyclones & $7.6 \%$ & $7.4 \%$ & $5.2 \%$ & $3.6 \%$ & $3.0 \%$ & $2.3 \%$ & $1.6 \%$ & $0.7 \%$ & $0.3 \%$ \\
\hline & Wet scrubbers & $46.3 \%$ & $40.4 \%$ & $19.0 \%$ & $6.9 \%$ & $6.1 \%$ & $5.0 \%$ & $3.9 \%$ & $3.1 \%$ & $2.5 \%$ \\
\hline & Electrostatic precipitators & $44.3 \%$ & $49.8 \%$ & $72.5 \%$ & $86.1 \%$ & $87.5 \%$ & $89.1 \%$ & $90.8 \%$ & $92.0 \%$ & $92.8 \%$ \\
\hline & Bag filters & $1.7 \%$ & $2.3 \%$ & $3.3 \%$ & $3.4 \%$ & $3.4 \%$ & $3.5 \%$ & $3.7 \%$ & $4.2 \%$ & $4.4 \%$ \\
\hline \multirow{3}{*}{ Fuel quality } & $\begin{array}{l}\text { Heating value } \\
\left(\mathrm{kJ} \mathrm{g}^{-1} \text { of coal }\right)\end{array}$ & 20.1 & 20.2 & 21.0 & 19.0 & 19.3 & 20.0 & 19.3 & 18.9 & 18.8 \\
\hline & $\begin{array}{l}\text { Coal consumption rate } \\
\left(\text { gce } \mathrm{kWh}^{-1}\right)\end{array}$ & 406.7 & 389.0 & 374.3 & 356.4 & 351.8 & 343.5 & 335.3 & 330.5 & 327.1 \\
\hline & Sulfur content $(\%)$ & 1.07 & 1.12 & 1.10 & 1.04 & 1.03 & 1.00 & 0.97 & 0.95 & 0.95 \\
\hline \multirow{10}{*}{$\begin{array}{l}\text { Emission } \\
\text { factor }\end{array}$} & $\mathrm{SO}_{2}\left(\mathrm{~g} \mathrm{kWh}^{-1}\right)$ & 10.73 & 9.82 & 9.15 & 8.69 & 7.47 & 5.34 & 4.06 & 3.00 & 2.48 \\
\hline & $\mathrm{NO}_{x}\left(\mathrm{~g} \mathrm{kWh}^{-1}\right)$ & 4.14 & 3.82 & 3.37 & 3.41 & 3.23 & 2.92 & 2.84 & 2.78 & 2.67 \\
\hline & $\mathrm{PM}_{2.5}\left(\mathrm{~g} \mathrm{kWh}^{-1}\right)$ & 2.34 & 1.84 & 1.12 & 0.73 & 0.62 & 0.48 & 0.39 & 0.31 & 0.27 \\
\hline & $\mathrm{PM}_{10}\left(\mathrm{~g} \mathrm{kWh}^{-1}\right)$ & 3.89 & 3.11 & 1.92 & 1.29 & 1.09 & 0.83 & 0.66 & 0.50 & 0.42 \\
\hline & $\mathrm{CO}_{2}\left(\mathrm{~g} \mathrm{kWh}^{-1}\right)$ & 1126.1 & 1077.1 & 1036.5 & 986.9 & 974.1 & 951.2 & 928.4 & 915.1 & 905.6 \\
\hline & $\mathrm{SO}_{2}\left(\mathrm{~g} \mathrm{~kg}^{-1}\right.$ of coal $)$ & 18.12 & 17.42 & 17.52 & 15.85 & 14.03 & 10.62 & 7.98 & 5.84 & 4.89 \\
\hline & $\mathrm{NO}_{x}\left(\mathrm{~g} \mathrm{~kg}^{-1}\right.$ of coal $)$ & 7.00 & 6.78 & 6.46 & 6.23 & 6.07 & 5.81 & 5.58 & 5.41 & 5.26 \\
\hline & $\mathrm{PM}_{2.5}\left(\mathrm{~g} \mathrm{~kg}^{-1}\right.$ of coal $)$ & 3.95 & 3.26 & 2.14 & 1.33 & 1.17 & 0.96 & 0.77 & 0.61 & 0.53 \\
\hline & $\mathrm{PM}_{10}\left(\mathrm{~g} \mathrm{~kg}^{-1}\right.$ of coal $)$ & 6.58 & 5.51 & 3.67 & 2.35 & 2.05 & 1.66 & 1.29 & 0.97 & 0.83 \\
\hline & $\mathrm{CO}_{2}\left(\mathrm{~g} \mathrm{~kg}^{-1}\right.$ of coal $)$ & 1902.9 & 1910.8 & 1984.8 & 1801.2 & 1828.1 & 1890.6 & 1822.9 & 1784.3 & 1781.9 \\
\hline \multirow{5}{*}{ Emissions } & $\mathrm{SO}_{2}\left(\mathrm{Tg} \mathrm{yr}^{-1}\right)$ & 4.94 & 7.74 & 9.27 & 16.70 & 16.73 & 14.15 & 10.96 & 8.22 & 7.71 \\
\hline & $\mathrm{NO}_{x}\left(\mathrm{Tg} \mathrm{yr}^{-1}\right)$ & 1.91 & 3.01 & 3.42 & 6.56 & 7.24 & 7.75 & 7.67 & 7.62 & 8.29 \\
\hline & $\mathrm{PM}_{2.5}\left(\mathrm{Tg} \mathrm{yr}^{-1}\right)$ & 1.08 & 1.45 & 1.13 & 1.40 & 1.39 & 1.28 & 1.06 & 0.85 & 0.83 \\
\hline & $\mathrm{PM}_{10}\left(\mathrm{Tg} \mathrm{yr}^{-1}\right)$ & 1.79 & 2.45 & 1.94 & 2.48 & 2.44 & 2.21 & 1.77 & 1.37 & 1.32 \\
\hline & $\mathrm{CO}_{2}\left(\mathrm{Pg} \mathrm{yr}^{-1}\right)$ & 0.52 & 0.85 & 1.05 & 1.90 & 2.18 & 2.52 & 2.51 & 2.51 & 2.81 \\
\hline
\end{tabular}

${ }^{a}$ Shares of coal consumption for each capacity size/technology.

small units (52\%). In addition, large units tend to have higher $\mathrm{SO}_{2}$ removal efficiencies. In 2010, large units contributed to $55 \%$ of the total $\mathrm{SO}_{2}$ emissions in 2010, while comprising $76 \%$ of the total capacity.

\subsection{2 $\mathrm{NO}_{x}$}

As shown in Fig. 4, $\mathrm{NO}_{x}$ emissions from power plants continued to increase from 1990 to 2010, except for the period of 2007-2009. $\mathrm{NO}_{x}$ emissions from power plants increased by a factor of 3.4 from 1990 to 2010 , from $1.9 \mathrm{Tg}$ (all of the values herein are calculated as $\mathrm{NO}_{2}$ ) in 1990 to $8.3 \mathrm{Tg}$ in 2010 . This dramatic growth was largely driven by the increasing electricity demand and was partially offset by the installation of LNB. Our study suggests that the average $\mathrm{NO}_{x}$ emission factor (in $\mathrm{g} \mathrm{kg}^{-1}$ of coal) slightly decreased at an annual rate of $1 \%$ from 1990 to 2005 with increasing LNB penetrations (Table 4). From 1990 to $2005, \mathrm{NO}_{x}$ emissions increased at an annual growth rate of $8.6 \%$, comparable to the $9.4 \%$ annual growth rate of coal consumption during the same period. After 2005, the decreased rate of average $\mathrm{NO}_{x}$ emissions accelerated (at $3 \%$ per year) because of the higher $\mathrm{NO}_{x}$ removal efficiencies of advanced LNB technologies compared with traditional LNB. From 2005 to $2010, \mathrm{NO}_{x}$ emissions increased by $126 \%$, which is remarkably lower than the $150 \%$ increase in coal consumption. Owing to the decline in emission factors and the reduction in electricity demand led by the global economic crisis, $\mathrm{NO}_{x}$ emissions decreased in 2008 and 2009 but increased again in 2010 at a growth rate of $9 \%$ after recovery from the economic crisis. 


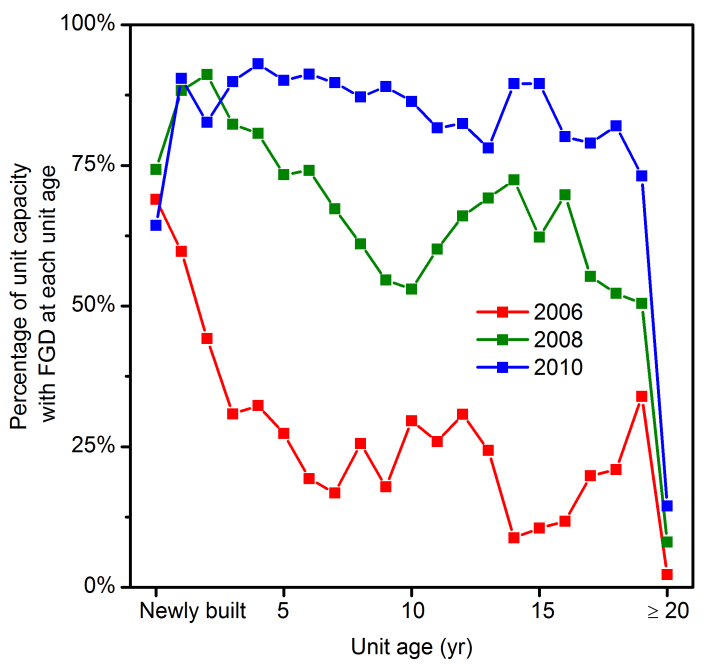

Figure 5. Distributions of FGD penetration for electric generating units of various ages in 2006, 2008, and 2010.

\subsubsection{PM}

$\mathrm{PM}_{2.5}$ and $\mathrm{PM}_{10}$ emissions from power plants decreased from 1.08 and $1.79 \mathrm{Tg}$ in 1990 to 0.83 and $1.32 \mathrm{Tg}$ in $2010 \mathrm{re}-$ spectively, with two fluctuating peaks occurring in 1996 and 2005, which were due to the combined effect of electricity demand and environmental regulations. Our estimates for the period of 1990-2005 are generally consistent with our previous estimates (Lei et al., 2011). The decline of emissions after the first peak was driven by the technology renewal progress following the implementation of the first emission standards for power plants in 1996 (SEPA, 1996), and the deceleration of the Chinese economy. PM emissions rebounded after the 1998 financial crisis but decreased again after 2005, in compliance with the implementation of stricter emission standards for power plants (SEPA, 2003). $\mathrm{PM}_{2.5}$ and $\mathrm{PM}_{10}$ emissions decreased by 40 and $47 \%$, respectively, from 2005 to 2010, which may be due to the following reasons. First, small units with poorly efficient PM emission control facilities were phased out from the unit fleet. Second, electrostatic precipitators and bag filters with high removal efficiencies were widely equipped in generation units under the requirement of the new emission standards. In addition, FGD installation further removed PM emissions from the end pipe. Due to the combination of these three factors, the average $\mathrm{PM}_{2.5}$ and $\mathrm{PM}_{10}$ emission factors decreased by 60 and $65 \%$, respectively, from 2005 to 2010 , completely offsetting the effect of the $50 \%$ increase in coal consumption.

\subsection{4 $\mathrm{CO}_{2}$}

Of the examined species emitted from power plants, $\mathrm{CO}_{2}$ emissions increased most rapidly from 1990 to 2010 because, in contrast to $\mathrm{SO}_{2}, \mathrm{NO}_{x}$, and $\mathrm{PM}_{2.5}$, no control measures were implemented to remove $\mathrm{CO}_{2}$. We estimated that

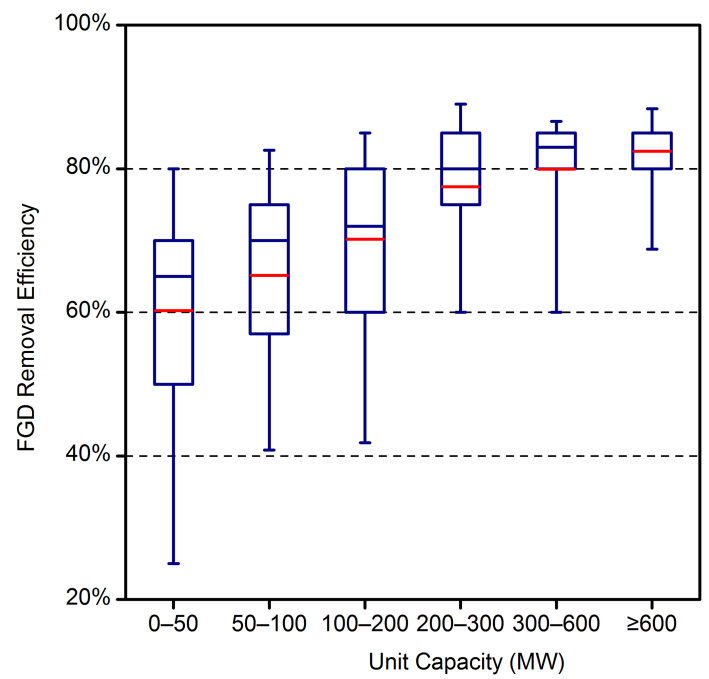

Figure 6. FGD removal efficiencies for electric generating units of various sizes in China in 2010. The blue horizontal line represents the median of the removal efficiencies, the red horizontal line represents the mean removal efficiencies, the box denotes the 25 and $75 \%$ percentiles, and the whiskers denote the 5 and $95 \%$ percentiles.

China's coal-fired power plants emitted $2.8 \mathrm{Pg} \mathrm{CO}_{2}$ in 2010 , an increase of $442 \%$ compared with emissions in 1990 . The increase is in line with the $574 \%$ growth in electricity generation (China Energy Statistical Yearbook, NBS, 1992-2011) but is slightly offset by the improved energy efficiency resulting from the spread of large and efficient units. Due to the improvement in energy efficiency, $\mathrm{CO}_{2}$ emissions per unit of electricity supplied were reduced by $20 \%$ from 1990 to 2010 , which is a great achievement, although far from constraining the growth of $\mathrm{CO}_{2}$ emissions.

\subsection{Evaluation of major policies for emission mitigation}

This section evaluates the effects of the major emission control measures on reducing $\mathrm{SO}_{2}, \mathrm{NO}_{x}, \mathrm{PM}_{2.5}$, and $\mathrm{CO}_{2}$ emissions during the 11th Five-Year Plan (2005-2010). As described in Sect. 3.1, China primarily implemented two policies for power plants during this period, including the installation of FGD and the optimization of the mix of generation unit fleets by promoting large power plants and decommissioning small plants. We developed two hypothetical scenarios to evaluate the effects of these two policies on emission mitigation, as follows. (1) Scenario I: we assumed that China did not adjust its fleet mix, i.e., its distribution of capacity size. In this scenario, the amount of newly built capacity is the same as the actual case, but the fleet mix was assumed to be unchanged during 2005 and 2010. (2) Scenario II: based on Scenario I, we further assumed that no new FGD installations were performed after 2005 . 


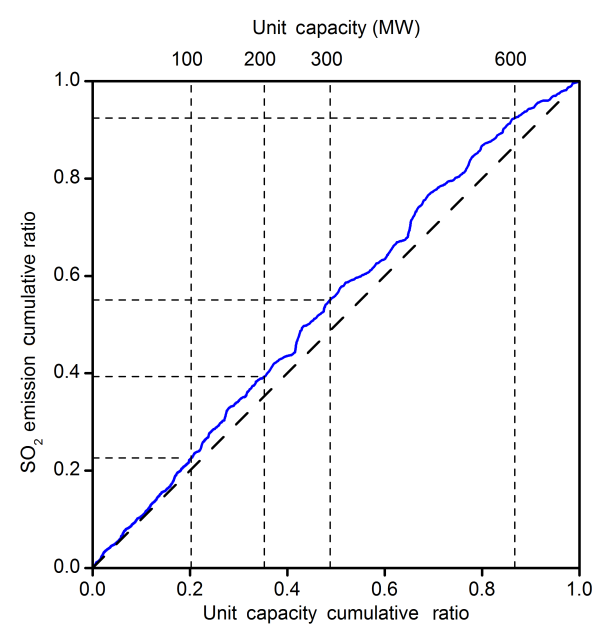

(a)

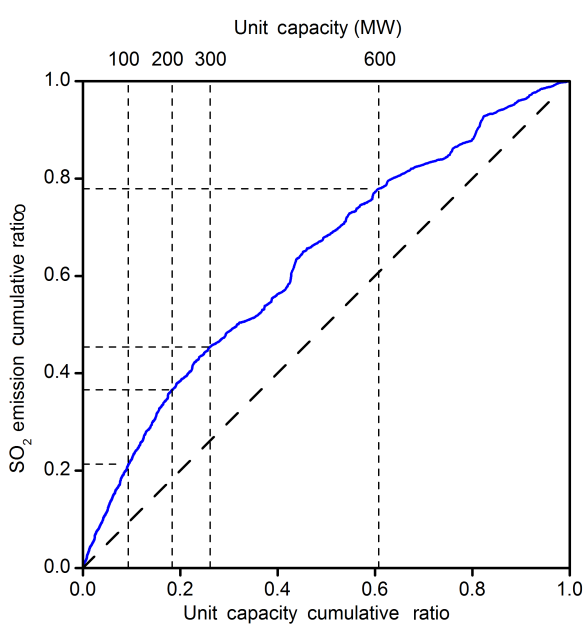

(b)

Figure 7. Cumulative ratio of $\mathrm{SO}_{2}$ emissions by unit capacity for the years (a) 2005 and (b) 2010. The units are sorted according to ascending capacity along the $x$ axis.

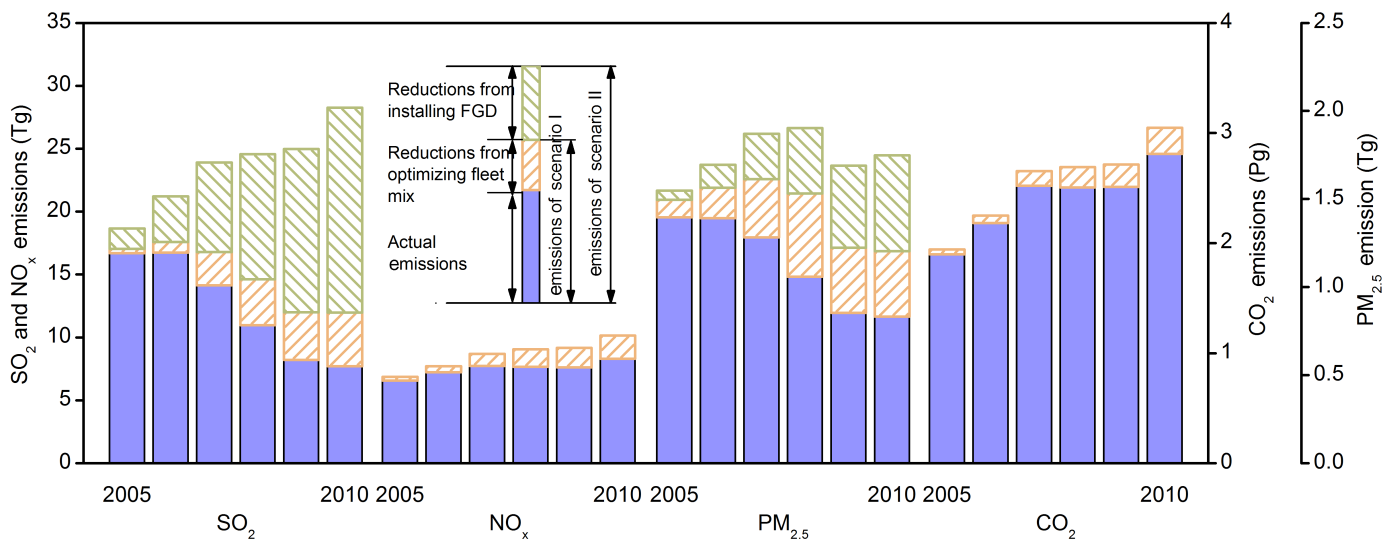

Figure 8. Reductions in $\mathrm{SO}_{2}, \mathrm{NO}_{x}, \mathrm{PM}_{2.5}$, and $\mathrm{CO}_{2}$ emissions from major emission control measures during the 11th Five-Year Plan (20052010). The solid blue bar denotes our estimates of interannual power plant emissions. The green and yellow bars illustrate the reduction in emissions due to FGD installations and optimization of the generation unit fleet mix, respectively.

Figure 8 compares the emission differences between the hypothetical scenarios I and II and the actual cases during 2005 and 2010. Restructuring the unit fleet resulted in coal savings by improving efficiency, which contributed to emission abatement for all of the species. In 2010, the restructuring aided in the reduction of $83.7 \mathrm{Tg}$ of coal use, $4.3 \mathrm{Tg}$ $\mathrm{SO}_{2}, 1.8 \mathrm{Tg} \mathrm{NO}_{x}, 0.4 \mathrm{Tg} \mathrm{PM}_{2.5}$, and 238.6 $\mathrm{Tg} \mathrm{CO}_{2}$ emissions compared with the hypothetical Scenario I.

The differences between the hypothetical Scenario I and Scenario II represent the effects of FGD installations. As shown in Fig. 8, FGD installation was a significant contributor to emission mitigation of $\mathrm{SO}_{2}$ and $\mathrm{PM}_{2.5}$. During the 6-year period from 2005 to 2010, FGD installation was estimated to reduce $51.6 \mathrm{Tg}$ of cumulative $\mathrm{SO}_{2}$ emissions or $36 \%$ of the cumulative $\mathrm{SO}_{2}$ emissions from power plants compared with the hypothetical Scenario II. In 2010, FGD installation prevented $16.3 \mathrm{Tg}$ of $\mathrm{SO}_{2}$ emissions, a value that is 2.1 times higher than the total actual emissions. In addition, FGD facilities aided in the reduction of $\mathrm{PM}_{2.5}$ by $0.54 \mathrm{Tg}$ in 2010, owing to the co-benefit of wet FGD on particulate matter removal.

\subsection{Spatial distribution of emissions}

Table 5 summarizes the unit fleet mix by capacity size and technology penetration rates, as well as the emission factors of China's six large interprovincial power grids, which are named according to the regions they serve, as follows: northeast China, north China, central China, east China, northwest China, and south China. A significant decrease in the emission factors of each of the five species can be observed for all of the power grids from 2005 to 2010, especially for $\mathrm{SO}_{2}$ and $\mathrm{PM}$, which is consistent with the national trend. The emission factors are different among the grids due to 
Table 5. Capacity sizes, technology penetrations, and emission factors of coal-fired power plants in China's six interprovincial power grids in 2005 and 2010 .

\begin{tabular}{|c|c|c|c|c|c|c|c|c|c|c|c|c|c|c|}
\hline \multirow[t]{2}{*}{ Year } & \multirow[t]{2}{*}{ Grid } & \multicolumn{4}{|c|}{ Capacity size $(\mathrm{MW})^{\mathrm{a}}$} & \multicolumn{3}{|c|}{ Technology penetration ${ }^{\mathrm{a}}$} & \multirow{2}{*}{$\begin{array}{r}\text { Sulfur } \\
\text { Content }(\%)\end{array}$} & \multicolumn{5}{|c|}{ Emission factor $\left(\mathrm{g} \mathrm{kWh}^{-1}\right)$} \\
\hline & & $(0,100)$ & $(100,300)$ & $(300,600)$ & $\geq 600$ & FGD & LNB & ESP & & $\mathrm{SO}_{2}$ & $\mathrm{NO}_{x}$ & $\mathrm{PM}_{2.5}$ & $\mathrm{PM}_{10}$ & $\mathrm{CO}_{2}$ \\
\hline \multirow{6}{*}{2005} & North & $20.0 \%$ & $29.6 \%$ & $36.4 \%$ & $14.0 \%$ & $14.5 \%$ & $62.6 \%$ & $89.1 \%$ & 1.05 & 8.74 & 3.36 & 0.66 & 1.20 & 954.6 \\
\hline & Northeast & $23.9 \%$ & $41.2 \%$ & $24.5 \%$ & $10.4 \%$ & $2.1 \%$ & $43.7 \%$ & $79.6 \%$ & 0.41 & 4.01 & 3.99 & 1.18 & 2.01 & 1094.0 \\
\hline & East & $17.6 \%$ & $18.4 \%$ & $39.7 \%$ & $24.3 \%$ & $27.1 \%$ & $70.5 \%$ & $92.2 \%$ & 0.74 & 5.28 & 2.96 & 0.45 & 0.78 & 958.9 \\
\hline & Central & $22.3 \%$ & $30.6 \%$ & $45.0 \%$ & $2.1 \%$ & $9.5 \%$ & $57.6 \%$ & $87.1 \%$ & 1.45 & 12.56 & 3.76 & 0.96 & 1.75 & 971.4 \\
\hline & Northwest & $23.3 \%$ & $29.4 \%$ & $40.4 \%$ & $6.9 \%$ & $0.2 \%$ & $59.9 \%$ & $92.0 \%$ & 1.21 & 11.09 & 3.40 & 0.69 & 1.23 & 1001.5 \\
\hline & South & $18.4 \%$ & $30.7 \%$ & $39.1 \%$ & $11.8 \%$ & $18.3 \%$ & $66.9 \%$ & $88.6 \%$ & 1.45 & 12.66 & 3.52 & 0.74 & 1.28 & 1038.2 \\
\hline \multirow{6}{*}{2010} & North & $11.1 \%$ & $21.4 \%$ & $38.4 \%$ & $29.2 \%$ & $88.0 \%$ & $81.4 \%$ & $91.0 \%$ & 1.00 & 2.45 & 2.79 & 0.26 & 0.41 & 914.7 \\
\hline & Northeast & $12.9 \%$ & $24.5 \%$ & $31.1 \%$ & $31.5 \%$ & $60.1 \%$ & $73.6 \%$ & $89.0 \%$ & 0.51 & 2.23 & 3.32 & 0.55 & 0.88 & 1042.9 \\
\hline & East & $10.0 \%$ & $7.1 \%$ & $25.7 \%$ & $57.2 \%$ & $94.3 \%$ & $87.2 \%$ & $96.2 \%$ & 0.69 & 1.26 & 2.28 & 0.16 & 0.25 & 877.3 \\
\hline & Central & $6.2 \%$ & $17.5 \%$ & $36.1 \%$ & $40.2 \%$ & $78.7 \%$ & $86.6 \%$ & $92.6 \%$ & 1.18 & 3.27 & 2.73 & 0.34 & 0.55 & 821.7 \\
\hline & Northwest & $10.1 \%$ & $20.2 \%$ & $39.8 \%$ & $29.9 \%$ & $77.0 \%$ & $83.8 \%$ & $95.7 \%$ & 0.98 & 3.44 & 2.78 & 0.27 & 0.43 & 956.7 \\
\hline & South & $4.4 \%$ & $14.4 \%$ & $39.8 \%$ & $41.4 \%$ & $92.7 \%$ & $91.4 \%$ & $98.0 \%$ & 1.32 & 3.41 & 2.56 & 0.20 & 0.31 & 904.4 \\
\hline
\end{tabular}

a Shares of coal consumption for each capacity size/technology.

their different mix of unit fleets, fuel qualities, and penetrations of emission control technologies. Of the six grids, the east and central grids exhibited the lowest $\mathrm{CO}_{2}$ emission factors in 2010, primarily due to their high percentage of large units in the generation mix (the capacity share of units larger than $300 \mathrm{MW}$ was more than $75 \%$ in 2010) and the higher combustion efficiency of large units. The variations of $\mathrm{SO}_{2}$ emission factors among the grids represent the differences in FGD penetration and the sulfur content of coal. The $\mathrm{SO}_{2}$ emission factors for the south and central grids are higher than the other grids due to the high sulfur content of coal. The FGD penetration rate of the northeast grid was significantly lower than that of the south grid in $2010(60.1 \%$ in the northeast vs. $92.7 \%$ in the south). However, the northeast grids had a lower $\mathrm{SO}_{2}$ emission factor $\left(2.23 \mathrm{~g} \mathrm{kWh}^{-1}\right.$ in the northeast vs. $3.41 \mathrm{~g} \mathrm{kWh}^{-1}$ in the south) due to the differences in the sulfur content of coal between the two regions. The $\mathrm{PM}_{2.5}$ emission factors varied remarkably due to the regional differences in the penetration rates of efficient $\mathrm{PM}_{2.5}$ removal facilities (electrostatic precipitators and bag filters). In 2010, the average $\mathrm{PM}_{2.5}$ emission factor in the northeast grid was more than 2 times higher than that of the east grid due to its lower penetration rates of electrostatic precipitators $(89.0 \%$ vs. $96.2 \%)$. Because an electrostatic precipitator has very high removal efficiency for $\mathrm{PM}_{2.5}(93 \%)$ compared with wet scrubbers $(50 \%)$ and cyclones $(10 \%)$, small differences in technology penetration among regions could result in significant disparities in the final emission factors.

Figure 9 depicts the yearly evolution of the $\mathrm{SO}_{2}$ emissions from China's coal-fired power plants from 1990 to 2010 at the unit level (only eastern China is shown on the map). New power plants were constructed throughout the country after 2000. Specifically, large units were rapidly constructed in the north regions, where large coal mines are located, and along the eastern coastal regions, where economies are most active. In addition, $\mathrm{SO}_{2}$ emissions from large units have declined significantly since 2005 , and many small units were terminated. Figure 10 shows $\mathrm{NO}_{x}$ emissions by unit for the years 1990, 2000, 2005, and 2010. In contrast to $\mathrm{SO}_{2}, \mathrm{NO}_{x}$ emissions continuously increased over the entire study period given that no effective $\mathrm{NO}_{x}$ emission control facilities (e.g., SCR) were operated after the generation units were commissioned.

\subsection{Monthly variation in emissions}

Figure 11 presents the monthly profiles of power generation, $\mathrm{CO}_{2}$ emissions, and $\mathrm{SO}_{2}$ emissions from 2005 to 2010, which were aggregated from the monthly profiles of each unit. Power generations and emissions typically peaked in December of each year due to high year-end industrial activities, with the exception of 2008 during the financial crisis. The second emission peak occurs in July and August, which is driven by the electricity demand of air conditioners. The low point of emissions occurs in January or February of each year, depending on the time of the Spring Festival.

As shown in Fig. 11, monthly variations in $\mathrm{CO}_{2}$ emissions generally follow the variation in power generation, whereas the monthly variation in $\mathrm{SO}_{2}$ emissions differs from that of the power generation after 2007 when FGD installations were widespread. After 2007, the monthly fraction of $\mathrm{SO}_{2}$ emissions was typically higher than the fraction of power generation during the first half of the year but reversed during the second half of the year, reflecting the fact that many FGD facilities were installed toward the end of the year to meet the government requirements of that year. In this case, the monthly emission profiles developed in this study differ from previous inventories for which temporal variations in power plant emissions were derived from the monthly electricity generation of each province (e.g., Streets et al., 2003; Zhang et al., 2007). 

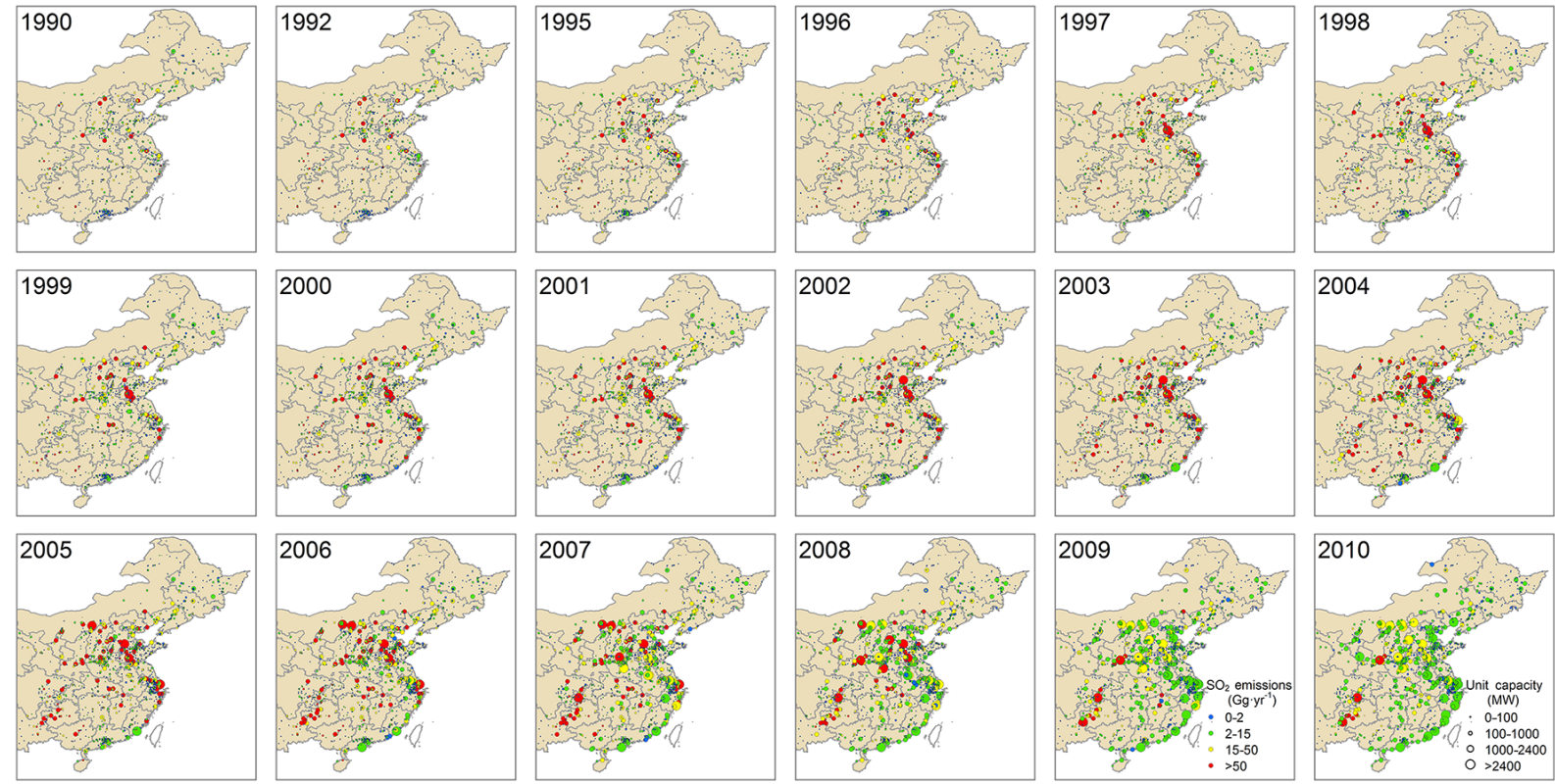

Figure 9. Evolution of $\mathrm{SO}_{2}$ emissions from coal-fired power plants in China, 1990-2010. Units: $\mathrm{Gg} \mathrm{yr}^{-1}$.
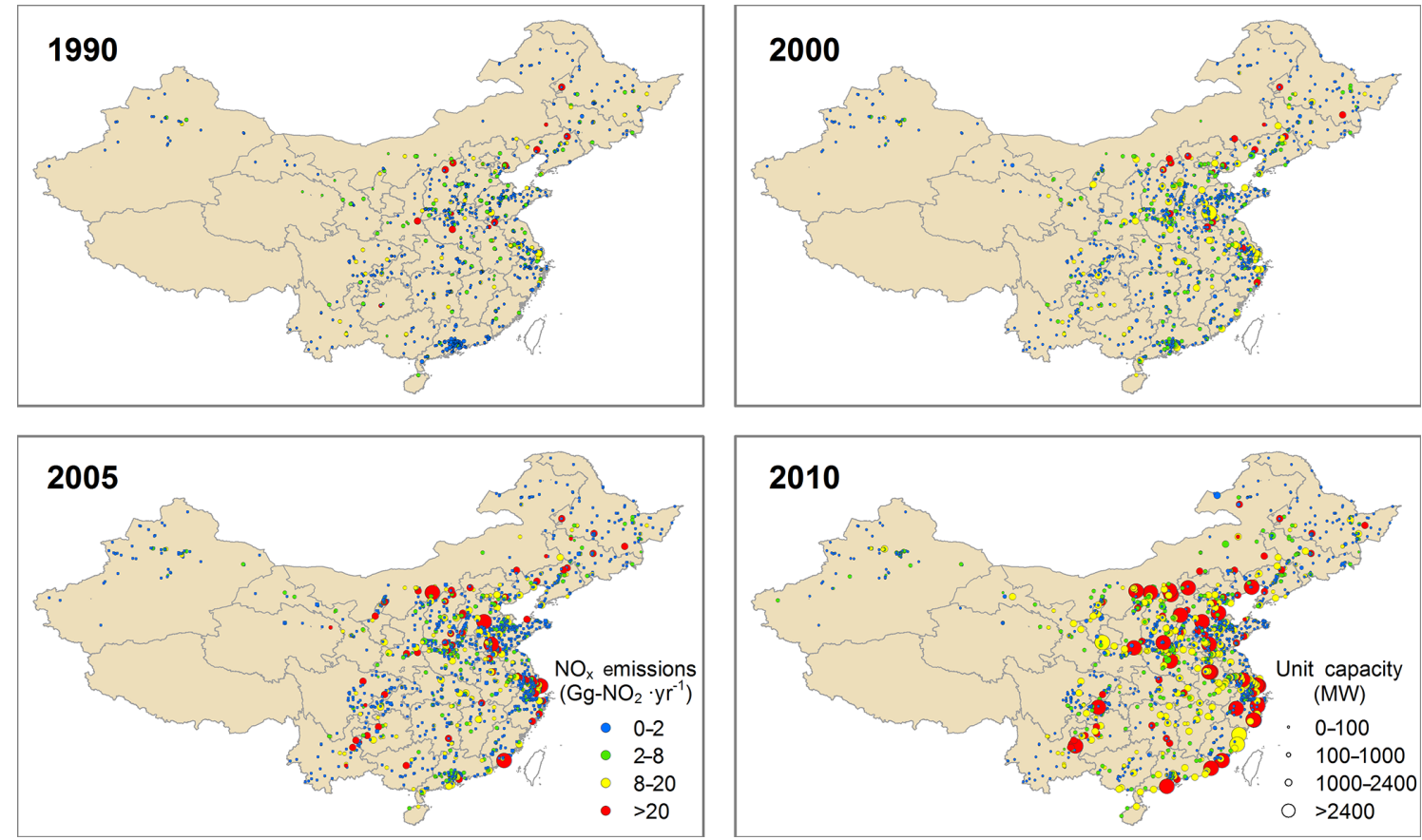

Figure 10. Spatial distribution of $\mathrm{NO}_{x}$ emissions from China's coal-fired power plants in 1990, 2000, 2005, and 2010. Units: $\mathrm{Gg}^{-\mathrm{NO}_{2}} \mathrm{yr}^{-1}$.

\section{Discussion}

\subsection{Uncertainty in emission estimates}

The uncertainty ranges of emissions estimated in this study are presented in Fig. 12. The average uncertainties of emissions from coal-fired power plants in China in 2010 are estimated as -22 to $23 \%$ for $\mathrm{SO}_{2},-15$ to $15 \%$ for $\mathrm{NO}_{x},-31$ to
$38 \%$ for $\mathrm{PM}_{2.5},-26$ to $30 \%$ for $\mathrm{PM}_{10}$, and -15 to $16 \%$ for $\mathrm{CO}_{2}$. The higher uncertainty range of the PM emission estimates is dominated by the uncertainties in the unabated emission factors and the efficiencies of PM removal facilities. The development of a local database of the actual removal efficiencies for emission control in the future will help to reduce the uncertainties. The uncertainty ranges narrowed gradually 


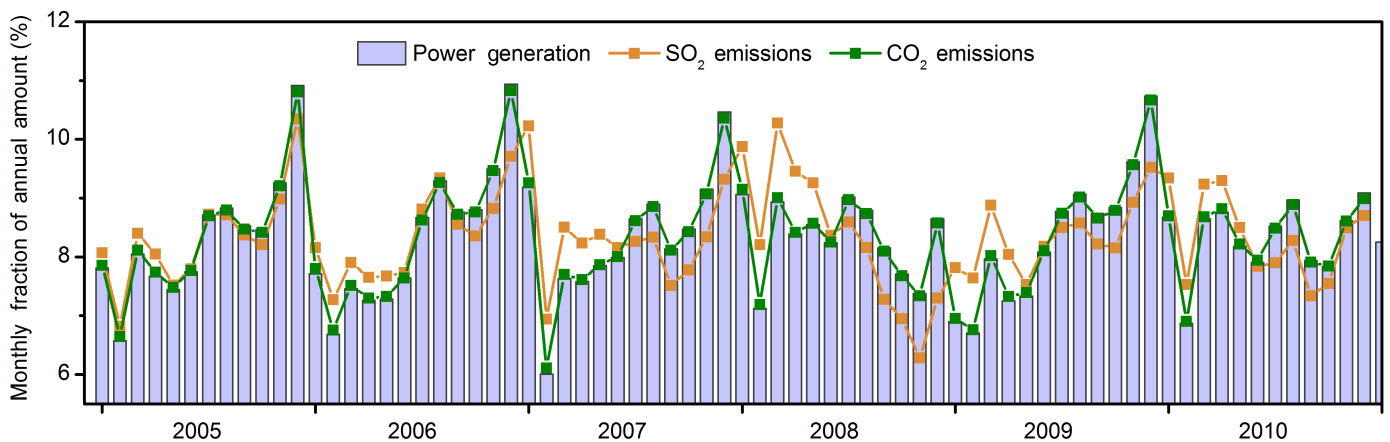

Figure 11. Monthly profiles of thermal power generation and coal-fired power-plant $\mathrm{SO}_{2}$ and $\mathrm{CO}_{2}$ emissions in China. The $y$ axis values represent the fraction of monthly emissions of annual emissions.

from 1990 to 2010, representing the improved knowledge of the underlying data over time. The uncertainty ranges declined from $-36-38,-24-26,-43-55,-32-39$, and -24 $27 \%$ in 1990 to $-22-23,-15-15,-31-38,-26-30$, and $-15-16 \%$ in 2010 for $\mathrm{SO}_{2}, \mathrm{NO}_{x}, \mathrm{PM}_{2.5}, \mathrm{PM}_{10}$, and $\mathrm{CO}_{2}$ respectively. As discussed in Sect. 2, many of the input data in the CPED in 1990 were determined by extrapolations and assumptions associated with high uncertainties, whereas the uncertainty ranges for the 2010 emission estimates are significantly reduced because of the extensive use of unit-specific data. The unit-specific annual coal use in 2010 contributed to the improved accuracy for all five species. In addition, a better understanding of sulfur content and removal efficiency of FGD, coal type, ash content, and heating value of coal for each unit in 2010, on which the accuracy of $\mathrm{SO}_{2}, \mathrm{NO}_{x}, \mathrm{PM}$, and $\mathrm{CO}_{2}$ emission factors depend, respectively, is the primary reason for the narrowed uncertainties for corresponding species.

We further demonstrated how the emission uncertainties changed over time at the unit level. For the selected generation unit (600 MW, pulverized boiler, equipped with FGD, LNB, and an electrostatic precipitator), the uncertainty ranges of the emission estimates for 2000 and 2010 are presented in Table 6 . The uncertainty ranges for the 2010 estimates are significantly reduced compared with the uncertainties for 2000 because more unit-specific information became available in 2010. For 2010, the uncertainties at the unit level are comparable with the national average, given that all of the available unit-specific input data correspond to low uncertainties. However, in 2000, the uncertainties at the unit level are significantly higher than the national average because several key parameters (e.g., annual operating hours, sulfur content and heating value of coal) were derived from extrapolations and assumptions.

In addition, we quantified uncertainties of other potential sources by sensitivity analysis. The assumption of $\mathrm{SO}_{2}$ removal efficiencies for FGD prior to 2008 may have underestimated $\mathrm{SO}_{2}$ emissions, as some of the early installed FGD facilities were not actually in operation then. Assuming $20 \%$
Table 6. Uncertainty ranges of emission estimates for a large coalfired generation unit (600 MW, pulverized boiler, equipped with FGD, LNB, and an electrostatic precipitator) in China; the values represent the $95 \% \mathrm{CI}$ around the mean.

\begin{tabular}{lrr}
\hline \multirow{2}{*}{ Species } & \multicolumn{2}{c}{ Year } \\
\cline { 2 - 3 } & 2000 & 2010 \\
\hline $\mathrm{SO}_{2}$ & $-58-56 \%$ & $-21-14 \%$ \\
$\mathrm{NO}_{x}$ & $-100-179 \%$ & $-28-47 \%$ \\
$\mathrm{PM}_{2.5}$ & $-61-95 \%$ & $-38-49 \%$ \\
$\mathrm{PM}_{10}$ & $-81-112 \%$ & $-39-44 \%$ \\
$\mathrm{CO}_{2}$ & $-28-33 \%$ & $-16-18 \%$ \\
\hline
\end{tabular}

of FGD did not operate properly, national total emissions could increase by 2, 4, and $9 \%$ for 2005, 2006, and 2007 respectively. The assumption of $\mathrm{PM}_{2.5}$ removal efficiency for wet FGD may have underestimated $\mathrm{PM}_{2.5}$ emissions for power plants with wet limestone-gypsum FGD. Particulate matters in desulfurizers of the spray slurry from scrubbers of wet FGD is likely to exhaust from stacks along with plumes. Those particulate matters would offset $\mathrm{PM}_{2.5}$ emissions absorbed by scrubbers of wet FGD (Meij and te Winkel, 2004). By assuming $10 \%$ changes of $\mathrm{PM}_{2.5}$ emissions are induced by gypsum spray (Meij and te Winkel, 2004), $\mathrm{PM}_{2.5}$ emissions could be increased by $0.3 \%$ in 2005 and $6.4 \%$ in 2010 , depending on the penetrations of wet FGD. We further quantified the uncertainties induced by the assumption that de$\mathrm{NO}_{x}$ devices were not in operation until 2010. By assuming that de- $\mathrm{NO}_{x}$ devices were put into operation in Beijing, Shanghai, and Guangdong in $2010, \mathrm{NO}_{x}$ emission estimates could be reduced by $67 \mathrm{Gg}$ ( $1 \%$ of national total emissions), indicating that our assumptions have small impacts on national total $\mathrm{NO}_{x}$ emission estimates. Overall, the sensitivity studies indicate that our assumptions have relatively small impacts on national total emission estimates. 


\subsection{Comparison with previous estimates of emission trends}

In this section, we compared our new inventory with other bottom-up emission inventories, as shown in Fig. 12, in which multi-year estimates are provided (more than five data points from 1990 to 2010). The discussion is focused on inventories that are available for multiple species and are widely used in the community, i.e., Emission Database for Global Atmospheric Research version 4.2 (EDGAR 4.2, ECJRC/PBL, 2011) and Regional Emission inventory in Asia version 2 (REAS 2, Kurokawa et al., 2013). We initially compared the $\mathrm{CO}_{2}$ emission estimates among the different emission inventories. Our estimate is consistent with Guan et al. (2012) but is approximately 16-25\% lower than the estimates by three other studies (EDGAR 4.2, REAS 2, and Y. Zhao et al., 2013). Our estimates are similar to those of Guan et al. (2012) because both estimates used a lower coal heating value (an average of $\sim 20 \mathrm{~kJ} \mathrm{~g}^{-1}$ ) derived from energy statistics, which was approximately $20 \%$ lower than the IPCC's recommended value $\left(25.8 \mathrm{~kJ} \mathrm{~g}^{-1}\right)$ used in other studies. The lower estimate in this study compared with EDGAR 4.2 might also be because the public electricity and heat production sector in EDGAR 4.2 includes emissions from heating plants.

For $\mathrm{SO}_{2}$ emissions, EDGAR 4.2 and the official estimates by the MEP (China Statistical Yearbook, NBS, 1997-2011) exceed the boundary of the $95 \%$ CI calculated in this study. EDGAR 4.2 estimated a positive trend until 2008, which differs from other studies, likely because EDGAR 4.2 failed to characterize the $\mathrm{SO}_{2}$ emission control progress in China's power plants after 2005. Three other inventories (REAS 2; Lu et al., 2011; and this study) provided consistent trajectories for $\mathrm{SO}_{2}$ emissions and are higher than the official estimates for the period of 1998 to 2008, likely due to underreported emissions by the MEP. All of the studies presented a similar growth trend for $\mathrm{NO}_{x}$ emissions over the last 2 decades, whereas EDGAR 4.2 and REAS 2 are slightly higher than the upper bound of the $95 \%$ CI calculated in this study. By revisiting the local emission factor measurements (Table 1), our new estimates for $\mathrm{NO}_{x}$ emissions are 15-24\% lower than previous estimates (Zhang et al., 2007) for the period of 1995-2004. REAS 2 used emission factors from Zhang et al. (2007) and then derived higher emissions than those in this study (Kurokawa et al., 2013). REAS 2 concluded that $\mathrm{NO}_{x}$ emissions from China's power plants increased by $136 \%$ from 2000 to 2008 , higher than the value of $125 \%$ of growth estimated in this study during the same period due to different assumptions in the evolution of combustion technologies. The PM emission trends presented in this study generally agree well with previous studies (Lei et al., 2011; Y. Zhao et al., 2013) but significantly differ from REAS 2. REAS 2 presented a $36 \%$ increase in $\mathrm{PM}_{2.5}$ emissions from 2005 to 2008 , whereas we estimated a $24 \%$ decrease during the same period, most likely due to different assumptions regarding the penetration of $\mathrm{PM}_{2.5}$ removal devices.

\subsection{Comparison with the CARMA database}

The CARMA database (Wheeler and Ummel, 2008; Ummel, 2012) has been widely used to allocate power plant emissions in different global and regional emission inventories (e.g., EDGAR 4.2 and REAS 2). In this section, we compared the magnitude and spatial distribution of $\mathrm{CO}_{2}$ emissions between this study and the CARMA database throughout China for 2009. The total magnitude of $\mathrm{CO}_{2}$ emissions for the two inventories is comparable, with a large discrepancy in the numbers of power plants. In this study, we estimated $2.51 \mathrm{Pg}$ $\mathrm{CO}_{2}$ emissions from 2320 power plants, whereas CARMA estimated $2.47 \mathrm{Pg} \mathrm{CO}_{2}$ emissions from 945 plants.

Figure 13a and $\mathrm{b}$ show the spatial distributions of $\mathrm{CO}_{2}$ emissions for CPED and the CARMA database, which illustrate that CARMA neglects many small power plants. Figure $13 \mathrm{c}$ depicts the cumulative curves of the power plant numbers sorted by $\mathrm{CO}_{2}$ emissions from low to high. In this study, power plants with annual $\mathrm{CO}_{2}$ emissions less than $1 \mathrm{Tg}$ accounted for $76 \%$ of the total plants, whereas the share of these plants was only $44 \%$ in CARMA. In summary, CARMA omitted $\sim 1300$ small power plants throughout China (annual $\mathrm{CO}_{2}$ emissions less than $1 \mathrm{Tg}$ ) in 2009. In addition, for power plants consisting of several generating units, CARMA may omit information on partial units. For example, the Tuoketuo power plant located in Inner Mongolia is composed of 10 generating units with a total capacity of $5400 \mathrm{MW}$. Its $\mathrm{CO}_{2}$ emission estimated by CARMA is $15.1 \mathrm{Tg}$, which is only $56 \%$ of the value estimated in this study, indicating CARMA's significant underestimation of coal consumption for the plant, which is most likely caused by missing information on some units.

Another major difference between the two inventories is the locations of the power plants and their emissions. Figure $13 \mathrm{~d}$ shows a magnified comparison of the spatial distributions of $\mathrm{CO}_{2}$ emissions between the two inventories over the southwest region of China, which illustrates the plantspecific emissions and locations. The power plant locations in CARMA deviate from those in our inventory due to the different geographical allocation methods used in the two data sets. In this study, the location of each power plant was obtained from the MEP database and was manually verified using Google Earth, which allowed for a high accuracy in the geographical distribution of emissions. CARMA generally treats the city-center latitudes and longitudes as the approximate coordinates of the power plants in China (Wheeler and Ummel, 2008). Ummel (2012) reported that the precise coordinates are only available for $10 \%$ of the plants worldwide in CARMA, and the reported emissions are within $20 \%$ of the actual values for only $75 \%$ of plants. For 46 power plants included in both CARMA and in CPED over the southwest region, the average distance between the locations reported 

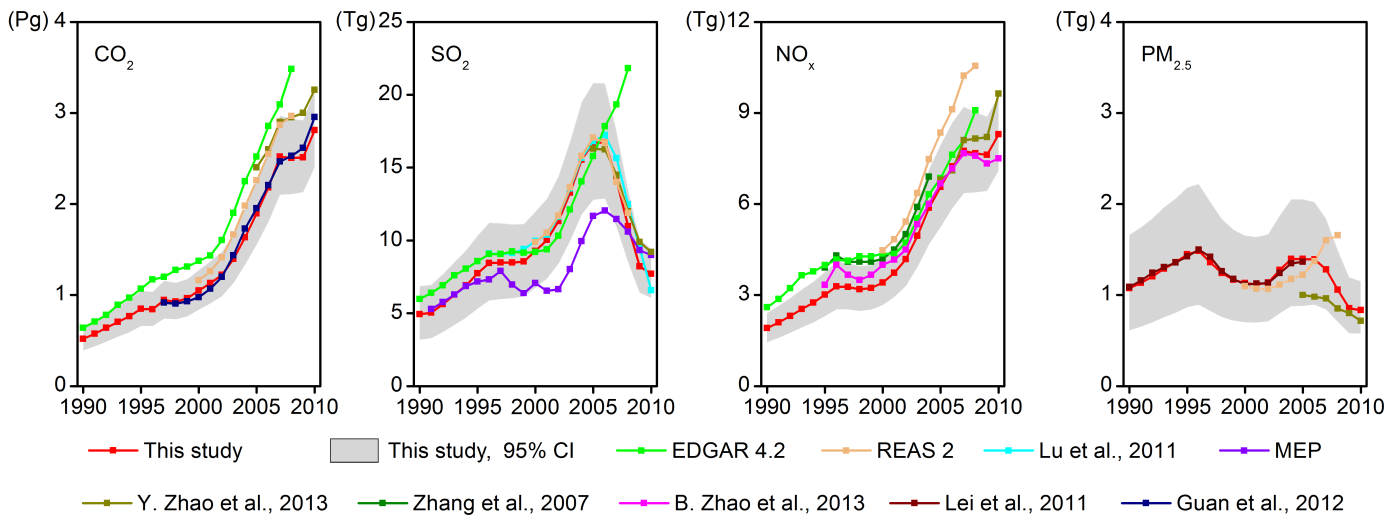

$\longrightarrow$ Y. Zhao et al., 2013

Figure 12. Comparisons of $\mathrm{SO}_{2}, \mathrm{NO}_{x}, \mathrm{PM}_{2.5}$ and $\mathrm{CO}_{2}$ emissions from China's coal-fired power plants during 1990 and 2010.
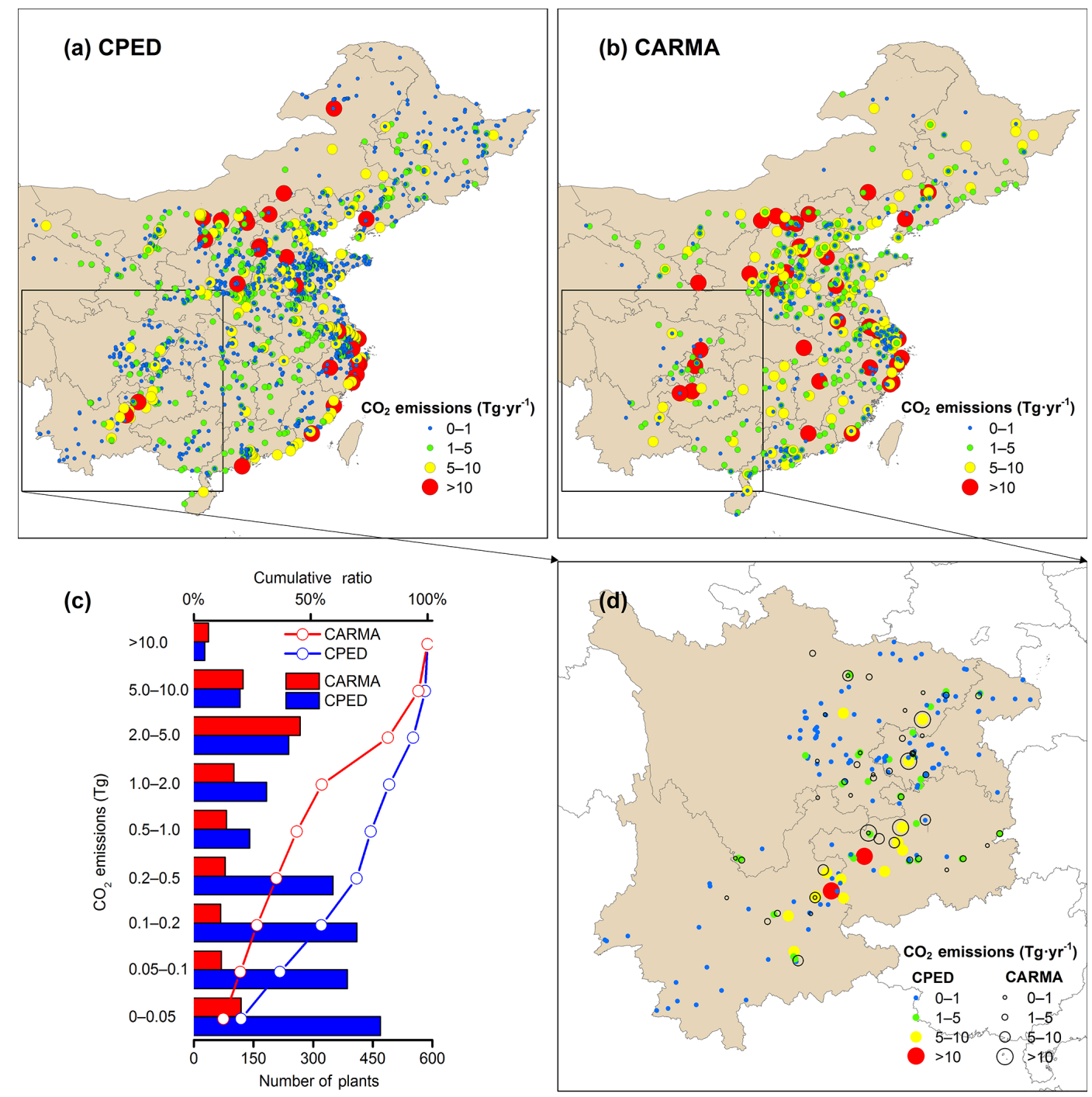

Figure 13. (a) Spatial distribution of $\mathrm{CO}_{2}$ emissions in CPED in 2009. (b) Spatial distribution of $\mathrm{CO}_{2}$ emissions in CARMA in 2009. (c) Comparisons of $\mathrm{CO}_{2}$ emissions between CARMA and CPED by plant numbers in 2009. The plants are sorted according to ascending $\mathrm{CO}_{2}$ emissions along the $y$ axis. The red and blue lines denote the plant number cumulative ratio for CARMA and CPED, respectively. (d) Comparisons of the spatial distribution of $\mathrm{CO}_{2}$ emissions in southwest China between CARMA and CPED in 2009. 

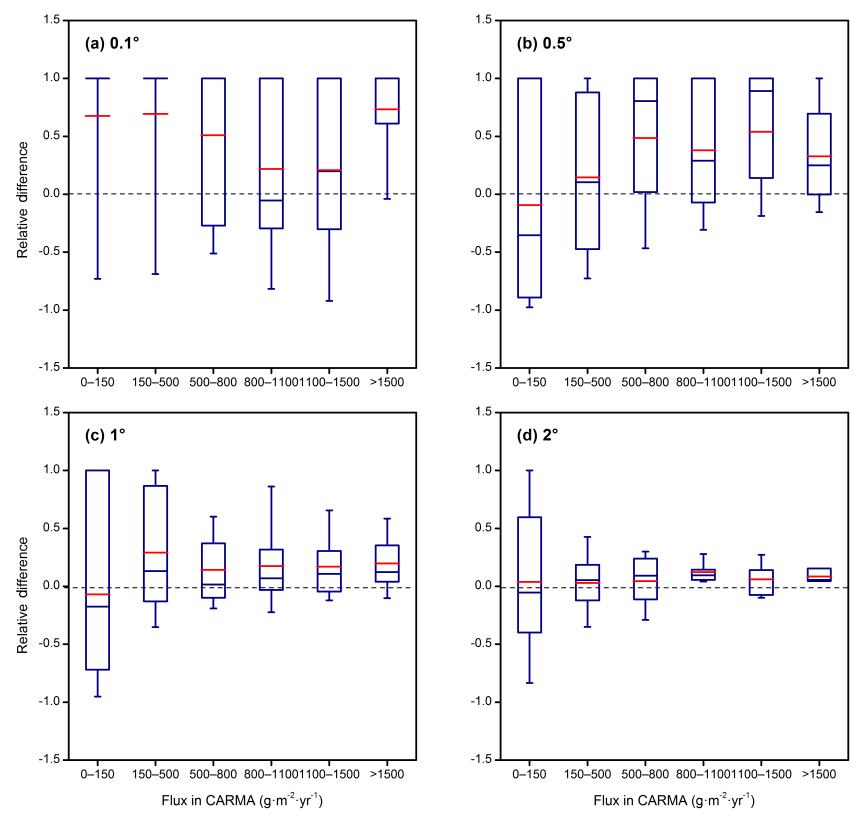

Figure 14. Comparisons of $\mathrm{CO}_{2}$ emissions between CARMA and CPED for various spatial resolutions (from 0.1 to $2^{\circ}$ ) in 2009 . The box plots show the binned relative differences $(a-b) /(a+b)$, where $a$ is the CARMA estimate, and $b$ is the CPED estimate. The blue horizontal line is the median of the relative differences, the red horizontal line is the mean of the relative differences, the box denotes the 25 and $75 \%$ percentiles, and the whiskers denote the 10 and $90 \%$ percentiles. A perfect agreement would correspond to a median and mean equal to 0 .

in CARMA and in CPED is approximately $50 \mathrm{~km}$, indicating that the CARMA database may be insufficient to support air quality modeling on regional and urban scales.

Figure 14 further presents the relative differences in the $\mathrm{CO}_{2}$ emission flux $\left(\mathrm{g} \mathrm{m}^{-2}\right)$ at various spatial resolutions $(0.1$, $0.5,1$, and $2^{\circ}$ ) in 2009 for the two data sets. The degree of differences between the two data sets is highly correlated to the spatial resolution. The differences are diminished as the spatial resolution decreases. The average differences between the two data sets are within $10 \%$ at a $2^{\circ}$ resolution and $20-30 \%$ at a $1^{\circ}$ resolution, indicating that CARMA has an acceptable accuracy to support modeling studies at the global scale. However, at a $0.1^{\circ}$ resolution, the relative differences between the two inventories are as high as $70 \%$, suggesting that CARMA is not appropriate for high-resolution modeling.

\section{Concluding remarks}

This is the first study to develop a unit-based inventory of technologies, activities, and emissions for China's coalfired power plants for the period of 1990-2010. The CPED database developed in this study includes $\sim 5700$ in-use electricity generating units in 2010 and $\sim 1900$ units that have retired since 2005. From the high-resolution CPED database, spatial and temporal variations of China's power plant emissions were presented from 1990 to 2010. In 2010, $\mathrm{SO}_{2}, \mathrm{NO}_{x}$, $\mathrm{PM}_{2.5}, \mathrm{PM}_{10}$, and $\mathrm{CO}_{2}$ emissions from China's coal-fired power plants were estimated to be $7.7,8.3,0.83,1.32 \mathrm{Tg}$, and $2.8 \mathrm{Pg}$ respectively. From 1990 to $2010, \mathrm{SO}_{2}, \mathrm{NO}_{x}$, and $\mathrm{CO}_{2}$ emissions from power plants increased by 56, 335, and $442 \%$, respectively, and $\mathrm{PM}_{2.5}$ and $\mathrm{PM}_{10}$ emissions decreased by 23 and $27 \%$ respectively during the same period. The energy efficiency of coal-fired power plants in China has been improved by approximately $20 \%$ in 20 years owing to measures imposed by the Chinese government to encourage large-scale power units and to decommission small units.

The most significant changes in power plant emissions occurred during 2005-2010, driven by the dramatic economic growth and offset by the strengthened emission control measures. Large units were rapidly constructed in the north regions and eastern coastal regions to meet the high electricity demand, while growth trend of emissions has been effectively curbed since 2005 by installation of FGD and the optimization of the generation fleet mix. $84 \%$ of the total unit capacities were equipped with FGD in 2010, which helped reducing $\mathrm{SO}_{2}$ emissions to half of the 2006 emission level. The increasing penetration of advanced LNB after 2006 has reduced the average $\mathrm{NO}_{x}$ emission factor by $16 \%$, but still did not constrain the growth of $\mathrm{NO}_{x}$ emissions. New environmental regulations, including the phaseout of small units with inefficient PM emission control facilities, the widespread use of electrostatic precipitators and bag filters, and FGD installations that are a co-benefit to PM removal, have led to the $40 \%$ decrease of $\mathrm{PM}_{2.5}$ emissions from 2005 to 2010.

Great emission reduction potentials from coal-fired power plants are expected in the near future through the implementation of new policies including the promotion of ultra-low emission units, the decommissioning of flue gas bypass systems, and the strengthening of supervision and management, etc. The removal efficiencies of existing FGD and de- $\mathrm{NO}_{x}$ devices are expected to be improved with the decommissioning of the flue gas bypass system. More efficient emission control technologies are expected to continuously come into the marketplace, with the implementation of the government plan (NDRC, 2014) which requires the reduction of emissions from coal-fired plants down to the level of gas-fired plants.

The new inventory developed in this work has several advantages as compared to previous studies. First, to the best of our knowledge, it is the most complete coal-fired power plant database for China with inclusion of 7657 inuse and retired units, enabling more accurate emission estimates at unit level. Second, CPED has dynamic information for a given unit including commission/decommission time of units, changes in technologies, and operating condition of emission control facilities. The above information further improved the accuracy of emission estimates for every time 
step. Third, exact locations of each unit were obtained from MEP and cross-checked by Google Earth manually, which could be a benefit to chemical transport modeling at high spatial resolution. The improved accuracy of CPED has been validated by another recent study using satellite-recorded tropospheric $\mathrm{NO}_{2}$ columns around the power plants (Liu et al., 2015). We also compared the NOx emission trends of two isolated power plants in CPED (Tuoketuo and Yangcheng) with OMI $\mathrm{NO}_{2}$ column trend (Fig. S1 in the Supplement). Good agreement between $\mathrm{NO}_{2}$ column trend and $\mathrm{NO}_{x}$ emission trend were found, indicating the reasonable accuracy of emission trend estimates in CPED. Detailed information for the comparison is presented in the supplementary information.

Although we believe that the accuracy of CPED has been substantially improved, it still has some uncertainties. Emission estimates for 1990s are thought to be more uncertain than in the 2000s because a few parameters during the 1990s were determined by extrapolations and assumptions rather than using unit-specific data. Units that retired before 2005 were not included in our database. However, we believe that omitting those units would have minor impacts on the accuracy of CPED, as large-scale retirement of coal-fired power plants only occurred after 2005. Local measurements for PM emission factors are still rare compared to $\mathrm{SO}_{2}$ and $\mathrm{NO}_{x}$, leading to higher uncertainties in PM emission estimates. In recent years, continuous emission monitoring systems (CEMS) were gradually equipped in electricity generating units, offering the opportunities of using real-time emission data. Applying CEMS data in the future will further improve the accuracy of emission estimates in CPED.

\section{Data availability}

The early version of CPED has been integrated into the MEIC (Multi-resolution Emission Inventory for China) database (both MEIC 1.0 and 1.2), which is available on the following website: http://www.meicmodel.org/. MEIC 1.0 was incorporated into the MIX Asian emission inventory ( $\mathrm{Li}$ et al., 2015). The most recent version of CPED (documented in this work) will be incorporated into the next version of MEIC.

\section{The Supplement related to this article is available online at doi:10.5194/acp-15-13299-2015-supplement.}

Acknowledgements. This study was supported by China's National Basic Research Program (2014CB441301) the National Natural Science Foundation of China (41222036, 41275026, and 71322304), and the EU FP-7 program MarcoPolo. Q. Zhang and K. B. He are supported by the Collaborative Innovation Center for Regional Environmental Quality. We would like to express special thanks to C. H. Chen, G. N. Geng, C. P. Hong, S. C. Kang, and S. W. Wang for cross-checking the locations of power plants.

Edited by: H. Su

\section{References}

Amann, M., Bertok, I., Borken-Kleefeld, J., Cofala, J., Heyes, C., Höglund-Isaksson, L., Klimont, Z., Nguyen, B., Posch, M., Rafaj, P., Sandler, R., Schöpp, W., Wagner, F., and Winiwarter, W.: Cost-effective control of air quality and greenhouse gases in Europe: Modeling and policy applications, Environ. Modell. Softw., 26, 1489-1501, 2011.

Bi, Y. and Chen, G.: Countermeasures and suggestions for controlling $\mathrm{NO}_{x}$ emission of utility boilers, Electricity, 15, 41-45, 2004 (in Chinese).

Cao, D. and Liu, H.: Study on $\mathrm{NO}_{x}$ emission control technology of boilers, Water Conservancy \& Electric Power Machinery, 33, 69-72, 2011 (in Chinese).

Chen, L., Sun, Y., Wu, X., Zhang, Y., Zheng, C., Gao, X., and Cen, K.: Unit-based emission inventory and uncertainty assessment of coal-fired power plants, Atmos. Environ., 99, 527-535, 2014.

European Commission (EC): Joint Research Centre (JRC)/Netherlands Environmental Assessment Agency (PBL).,Emission Database for Global Atmospheric Research (EDGAR), release version 4.2., http://edgar.jrc.ec.europa.eu, (last access: 1 December 2013), 2011.

Feng, M. and Yan, H.: Research on the concentration value conversion of $\mathrm{NO}_{x}$ in the flue gas from thermal power plants, Shanxi Eletric Power, 143, 14-20, 2007 (in Chinese).

Guan, D., Liu, Z., Geng, Y., Lindner, S., and Hubacek, K.: The gigatonne gap in China's carbon dioxide inventories, Nature Climate Change, 2, 672-675, 2012.

Gurney, K.: Interactive comment on "High resolution mapping of combustion processes and implications for $\mathrm{CO}_{2}$ emissions" by R. Wang et al., Atmos. Chem. Phys. Discuss., C7856-C7859, 2012.

Hao, J., Tian, H., and Lu, Y.: Emission inventories of $\mathrm{NO}_{x}$ from commercial energy consumption in China, 1995-1998, Environ. Sci. Technol., 36, 552-560, 2002.

Intergovernmental Panelon Climate Change (IPCC): 2006 IPCC guidelines for national greenhouse gas inventories, 20-24, 2006.

Kato, N. and Akimoto, H.: Anthropogenic emissions of $\mathrm{SO}_{2}$ and $\mathrm{NO}_{x}$ in Asia: emission inventories, Atmos. Environ., 26, 2997 3017, 1992.

Klimont, Z., Cofala, J., Schöpp, W., Amann, M., Streets, D. G., Ichikawa, Y., and Fujita, S.: Projections of $\mathrm{SO}_{2}, \mathrm{NO}_{x}, \mathrm{NH}_{3}$ and VOC emissions in East Asia up to 2030, Water Air Soil Pollut., 130, 193-198, 2001.

Klimont, Z., Cofala, J., Bertok, I., Amann, M., Heyes, C., and Gyarfas, F.: Modeling Particulate Emissions in Europe: A framework to estimate reduction potential and control costs, Interim report, IR-02-076, International Institute for Applied Systems Analysis, Laxenburg, Austria, 169 pp., 2002.

Klimont, Z., Cofala, J., Xing, J., Wei, W., Zhang, C., Wang, S., Kejun, J., Bhandari, P., Mathur, R., Purohit, P., Rafaj, P., Chambers, A., and Amann, M.: Projections of $\mathrm{SO}_{2}, \mathrm{NO}_{x}$ and carbonaceous aerosols emissions in Asia, Tellus B, 61, 602-617, 2009. 
Klimont, Z., Smith, S. J., and Cofala, J.: The last decade of global anthropogenic sulfur dioxide: 2000-2011 emissions, Environ. Res. Lett., 8, 014003, doi:10.1088/1748-9326/8/1/014003, 2013.

Kurokawa, J., Ohara, T., Morikawa, T., Hanayama, S., JanssensMaenhout, G., Fukui, T., Kawashima, K., and Akimoto, H.: Emissions of air pollutants and greenhouse gases over Asian regions during 2000-2008: Regional Emission inventory in ASia (REAS) version 2, Atmos. Chem. Phys., 13, 11019-11058, doi:10.5194/acp-13-11019-2013, 2013.

Lei, Y., Zhang, Q., He, K. B., and Streets, D. G.: Primary anthropogenic aerosol emission trends for China, 1990-2005, Atmos. Chem. Phys., 11, 931-954, doi:10.5194/acp-11-931-2011, 2011.

Li, C., Zhang, Q., Krotkov, N. A., Streets, D. G., He, K. B., Tsay, S.-C., and Gleason, J. F.: Recent large reduction in sulfur dioxide emissions from Chinese power plants observed by the Ozone Monitoring Instrument, Geophys. Res. Lett., 37, L08807, doi:10.1029/2010GL042594, 2010.

Li, M., Zhang, Q., Kurokawa, J., Woo, J.-H., He, K. B., Lu, Z., Ohara, T., Song,Y., Sreets, D. G., Carmichael, G. R., Cheng, Y. F., Huo, H., Liu, F., Su, H., and Zheng, B.: MIX: a mosaic Asian anthropogenic emission inventory for the MICS-Asia and the HTAP projects, Atmos. Phys. Chem. Discuss., submitted, 2015.

Liu, F., Beirle, S., Zhang, Q., Dörner, S., He, K. B., and Wagner, T.: $\mathrm{NO}_{x}$ lifetimes and emissions of hotspots in polluted background estimated by satellite observations, Atmos. Chem. Phys. Discuss., 15, 24179-24215, doi:10.5194/acpd-15-241792015, 2015.

Liu, Y.: Discussing on countermeasures and influence of varied coal quality in fired power plants, Coal Quality Technology, 6, 1-3, 2007 (in Chinese).

Lu, Z., Streets, D. G., Zhang, Q., Wang, S., Carmichael, G. R., Cheng, Y. F., Wei, C., Chin, M., Diehl, T., and Tan, Q.: Sulfur dioxide emissions in China and sulfur trends in East Asia since 2000, Atmos. Chem. Phys., 10, 6311-6331, doi:10.5194/acp-106311-2010, 2010.

Lu, Z., Zhang, Q., and Streets, D. G.: Sulfur dioxide and primary carbonaceous aerosol emissions in China and India, 1996-2010, Atmos. Chem. Phys., 11, 9839-9864, doi:10.5194/acp-11-98392011, 2011.

Meij, R., and te Winkel, B.: The emissions and environmental impact of $\mathrm{PM}_{10}$ and trace elements from a modern coalfired power plant equipped with ESP and wet FGD, Fuel Process. Technol., 85, 641-656, 2004.

National Bureau of Statistics (NBS): China Energy Statistical Yearbook (1990, 1991-1996, 1997-1999, 2000-2002, 2004, 2005, 2006, 2007, 2008, 2009, 2010 editions), China Statistics Press: Beijing, China, 1992-2011.

National Bureau of Statistics (NBS): China Statistical Yearbook, China Statistics Press, Beijing, China, 4, 1997-2011.

National Bureau of Statistics (NBS): China Statistical Database, availabe at http://data.stats.gov.cn/, last accessed: 5 December 2013.

National Development and Reform Commission (NDRC): List of retired electric generating units in China, available at: http://bgt. ndrc.gov.cn/zcfb/, last access: 5 December 2013 (in Chinese).

National Development and Reform Commission (NDRC): Clean coal-fired power plants action plan (2014-2020), available at: http://www.sdpc.gov.cn/gzdt/201409/t20140919_626240.html (last access: 10 September 2015), 2014 (in Chinese).
Oda, T. and Maksyutov, S.: A very high-resolution $(1 \mathrm{~km} \times 1 \mathrm{~km})$ global fossil fuel $\mathrm{CO}_{2}$ emission inventory derived using a point source database and satellite observations of nighttime lights, Atmos. Chem. Phys., 11, 543-556, doi:10.5194/acp-11-543-2011, 2011.

Ohara, T., Akimoto, H., Kurokawa, J., Horii, N., Yamaji, K., Yan, X., and Hayasaka, T.: An Asian emission inventory of anthropogenic emission sources for the period 1980-2020, Atmos. Chem. Phys., 7, 4419-4444, doi:10.5194/acp-7-4419-2007, 2007.

Qian, C.: Study on air staged low $\mathrm{NO}_{x}$ emission combustion technology, Shanghai Electricity, 1, 38-40, 2010 (in Chinese).

Shen, L. and Song, S.: Effects of coal quality on boiler and countermeasures, Shandong Electric Power, 37-41, 2010 (in Chinese).

State Environmental Protection Administration of China (SEPA): Emission Standard of Air Pollutants for Thermal Power Plants: GB 13223-1996, China Environmental Science Press, Beijing, China, 4, 1996.

State Environmental Protection Administration of China (SEPA): Emission Standard of Air Pollutants for Thermal Power Plants: GB 13223-2003, China Environmental Science Press, Beijing, China, 3, 2003.

Streets, D. G., Bond, T. C., Carmichael, G. R., Fernandes, S. D., Fu, Q., He, D., Klimont, Z., Nelson, S. M., Tsai, N. Y., Wang, M. Q., Woo, J. H., and Yarber, K. F.: An inventory of gaseous and primary aerosol emissions in Asia in the year 2000, J. Geophys. Res., 108, 8809, doi:10.1029/2002jd003093, 2003.

Tang, S., Sun, S., Qin, Y., Jiang, Y., and Wang, W.: Distribution characteristics of sulfur and the main harmful trace elements in China's coal, Acta Geologica Sinica - English Edition, 82, 722730, 2008.

Tian, H.: Studies on present and future emissions of nitrogen oxides and its comprehensive control policies in China, $\mathrm{PhD}$ thesis, Tsinghua University, Beijing, 59-63, 2003 (in Chinese).

Tian, H., Liu, K., Hao, J., Wang, Y., Gao, J., Qiu, P., and Zhu, C.: Nitrogen oxides emissions from thermal power plants in China: Current status and future predictions, Environ. Sci. Technol., 47, 11350-11357, 2013.

Ummel, K.: CARMA revisited: An updated database of carbon dioxide emissions from power plants worldwide, Center for Global Development, Working Paper 304 pp., 2012.

Wang, R., Tao, S., Ciais, P., Shen, H. Z., Huang, Y., Chen, H., Shen, G. F., Wang, B., Li, W., Zhang, Y. Y., Lu, Y., Zhu, D., Chen, Y. C., Liu, X. P., Wang, W. T., Wang, X. L., Liu, W. X., Li, B. G., and Piao, S. L.: High-resolution mapping of combustion processes and implications for $\mathrm{CO}_{2}$ emissions, Atmos. Chem. Phys., 13, 5189-5203, doi:10.5194/acp-13-5189-2013, 2013.

Wang, S. W., Zhang, Q., Streets, D. G., He, K. B., Martin, R. V., Lamsal, L. N., Chen, D., Lei, Y., and Lu, Z.: Growth in $\mathrm{NO}_{x}$ emissions from power plants in China: bottom-up estimates and satellite observations, Atmos. Chem. Phys., 12, 4429-4447, doi:10.5194/acp-12-4429-2012, 2012.

Wang, S. W., Zhang, Q., Martin, R. V., Philip, S., Liu, F., Li, M., Jiang, X. J., and He, K. B.: Satellite measurements oversee China's sulfur dioxide emission reductions from coal-fired power plants, Environ. Res. Letts., 10, 114015, 2015.

Wang, X., Xin, H., Luan, T., and Cheng, L.: Research and test on influence of boiler combustion adjusting on $\mathrm{NO}_{x}$ emission 
of 330MW unit, Power System Engineering, 23, 7-10, 2007 (in Chinese).

Wang, X., Luan, T., and Cheng, L.: Experimental study on performance and $\mathrm{NO}_{x}$ emission of large coal-fired boilers, Power Equipment, 6, 467-472, 2008 (in Chinese).

Wheeler, D. and Ummel, K.: Calculating CARMA: Global estimation of $\mathrm{CO}_{2}$ emissions from the power sector, Center for Global Development, Working Paper 145, 2008.

Xie, J., Zhang, S., and Xia, Y.: Analysis of performance and $\mathrm{NO}_{x}$ emission of 600MW boilers, Dongfang Boiler, 3, 12-16, 2008 (in Chinese).

Xie, Z.: Wet dedusting, desulfurization and denitrification without using additives for coal-fired boilers, China Environmental Protection Industry, 3, 22-23, 1995 (in Chinese).

$\mathrm{Xu}$, Y.: China's functioning market for sulfur dioxide scrubbing technologies, Environ. Sci. Technol., 45, 9161-9167, 2011.

Xu, Y., Williams, R. H., and Socolow, R. H.: China's rapid deployment of $\mathrm{SO}_{2}$ scrubbers, Energy \& Environmental Science, 2, 459-465, 2009.

Yao, W.: Experiment on the $\mathrm{SO}_{2}$ removal efficiency of wet scrubbers, Environmental Protection, 2, 11-13, 1989 (in Chinese).

Yi, H. H., Hao, J. M., Duan, L., Li, X. H., and Guo, X. M.: Characteristics of inhalable particulate matter concentration and size distribution from power plants in China, J. Air Waste Manage., 56, 1243-1251, 2006.

Zhang, L., Wang, S., Meng, Y., and Hao, J.: Influence of mercury and chlorine content of coal on mercury emissions from coalfired power plants in China, Environ. Sci. Technol., 46, 63856392, 2012.

Zhang, Q., Streets, D. G., He, K., Wang, Y., Richter, A., Burrows, J. P., Uno, I., Jang, C. J., Chen, D., Yao, Z., and Lei, Y.: $\mathrm{NO}_{x}$ emission trends for China, 1995-2004: The view from the ground and the view from space, J. Geophys. Res., 112, D22306, doi:10.1029/2007jd008684, 2007.

Zhang, Q., Streets, D. G., Carmichael, G. R., He, K. B., Huo, H., Kannari, A., Klimont, Z., Park, I. S., Reddy, S., Fu, J. S., Chen, D., Duan, L., Lei, Y., Wang, L. T., and Yao, Z. L.: Asian emissions in 2006 for the NASA INTEX-B mission, Atmos. Chem. Phys., 9, 5131-5153, doi:10.5194/acp-9-5131-2009, 2009a.
Zhang, X., Sun, R., Sun, S., and Qin, M.: Effects of stereo-staged combustion technique on $\mathrm{NO}_{x}$ emission charactisctics, J. Mech. Eng., 45, 199-205, 2009b (in Chinese).

Zhao, B., Wang, S. X., Liu, H., Xu, J. Y., Fu, K., Klimont, Z., Hao, J. M., He, K. B., Cofala, J., and Amann, M.: $\mathrm{NO}_{x}$ emissions in China: historical trends and future perspectives, Atmos. Chem. Phys., 13, 9869-9897, doi:10.5194/acp-13-9869-2013, 2013.

Zhao, Y., Wang, S., Duan, L., Lei, Y., Cao, P., and Hao, J.: Primary air pollutant emissions of coal-fired power plants in China: Current status and future prediction, Atmos. Environ., 42, 84428452, 2008.

Zhao, Y., Wang, S., Nielsen, C. P., Li, X., and Hao, J.: Establishment of a database of emission factors for atmospheric pollutants from Chinese coal-fired power plants, Atmos. Environ., 44, 1515-1523, 2010.

Zhao, Y., Nielsen, C. P., Lei, Y., McElroy, M. B., and Hao, J.: Quantifying the uncertainties of a bottom-up emission inventory of anthropogenic atmospheric pollutants in China, Atmos. Chem. Phys., 11, 2295-2308, doi:10.5194/acp-11-2295-2011, 2011.

Zhao, Y., Zhang, J., and Nielsen, C. P.: The effects of recent control policies on trends in emissions of anthropogenic atmospheric pollutants and $\mathrm{CO}_{2}$ in China, Atmos. Chem. Phys., 13, 487-508, doi:10.5194/acp-13-487-2013, 2013.

Zheng, B., Huo, H., Zhang, Q., Yao, Z. L., Wang, X. T., Yang, X. F., Liu, H., and He, K. B.: High-resolution mapping of vehicle emissions in China in 2008, Atmos. Chem. Phys., 14, 9787-9805, doi:10.5194/acp-14-9787-2014, 2014.

Zhu, F., Wang, S., and Zheng, Y.: $\mathrm{NO}_{x}$ emitting current situation and forecast from thermal power plants and countermeasures, Energy Environmental Protection, 18, 1-5, 2004 (in Chinese).

Zhu, F., Liu, D., and Wang, S.: Overview of $\mathrm{NO}_{x}$ emissions and control measures from thermal power plants, Environmental Protection, 21, 40-41, 2009 (in Chinese).

Zhu, F.: Study on $\mathrm{NO}_{x}$ emission reduction potential and gross control measures of thermal power plants in China, State Power Environmental Protection Research Institute, Nanjing, 22-27, 2011 (in Chinese).

Zhu, L.: Modification of low nitrogen oxide combustion for 300MW coal-fired boiler, Guangdong Electric Power, 22, 64-67, 2009 (in Chinese). 